\title{
Validation of TRMM Precipitation Radar through Comparison of its Multi-Year Measurements to Ground-Based Radar
}

\author{
Liang Liao \\ Goddard Earth Sciences \& Technology Center/UMBC, Greenbelt, MD 20771 \\ Robert Meneghini \\ Code 613.1, NASA/GSFC, Greenbelt, MD 20771
}

Submitted to

Journal of Applied Meteorology and Climatology

Corresponding author information:

Dr. Liang Liao

Goddard Earth Science Technology/UMBC

Code 613.1

NASA/Goddard Space Flight Center

Greenbelt, MD 20771

301-614-5718 (phone)

301-614-5558 (fax)

Email: Liang.Liao-1@ nasa.gov 


\begin{abstract}
A procedure to accurately resample spaceborne and ground-based radar data is described, and then applied to the measurements taken from the Tropical Rainfall Measuring Mission (TRMM) Precipitation Radar (PR) and the ground-based Weather Surveillance Radar-1988 Doppler (WSR-88D or WSR) for the validation of the PR measurements and estimates. Through comparisons with the well-calibrated, non-attenuated WSR at Melbourne, Florida for the period 1998-2007, the calibration of the Precipitation Radar (PR) aboard the TRMM satellite is checked using measurements near the storm top. Analysis of the results indicates that the PR, after taking into account differences in radar reflectivity factors between the PR and WSR, has a small positive bias of $0.8 \mathrm{~dB}$ relative to the WSR, implying a soundness of the PR calibration in view of the uncertainties involved in the comparisons. Comparisons between the PR and WSR reflectivities are also made near the surface for evaluation of the attenuation-correction procedures used in the PR algorithms. It is found that the PR attenuation is accurately corrected in stratiform rain but is underestimated in convective rain, particularly in heavy rain. Tests of the PR estimates of rainfall rate are conducted through comparisons in the overlap area between the TRMM overpass and WSR scan. Analyses of the data are made both on a conditional basis, in which the instantaneous rain rates are compared only at those pixels where both the PR and WSR detect rain, and an unconditional basis, in which the area-averaged rain rates are estimated independently for the PR and WSR. Results of the conditional rain comparisons show that the PR-derived rain is about $9 \%$ greater and $19 \%$ less than the WSR estimates for stratiform and convective storms, respectively. Overall, the PR tends to underestimate the conditional mean rain rate by $8 \%$ for all rain categories, a finding that conforms to the results of the area-averaged rain (unconditional) comparisons.
\end{abstract}




\section{Introduction}

The Precipitation Radar (PR) aboard the Tropical Rainfall Measuring Mission (TRMM) has been operating nearly flawlessly since the launch of the satellite in 1997 . The PR is the first active microwave instrument for measuring 3-dimensional rain structures over the tropics and subtropics (Kozu et al., 2001; Simpson et al., 1988; Kummerow et al., 2000). Validation of precipitation estimates from the PR is essential to the success of the TRMM mission (Marks et al. 2000; Liao et al. 2001; Amitai et al. 2004, 2005; Wolff et al. 2005). Operating at a frequency of $13.8 \mathrm{GHz}$ (Ku band), the PR is subject to attenuation from cloud water, rain and partially melted hydrometeors. The correction for attenuation is therefore one of the most important procedures in the estimation of rain rate. A hybrid scheme (Iguchi et al. 2000) is applied to the TRMM PR data to infer rain attenuation. This is a combination of the surface reference technique, SRT (Meneghini et al. 2000) and the Hitschfeld-Bordan method (1954). Comparisons of the unattenuated radar reflectivities from the ground-based radar to the attenuation-corrected radar reflectivities from the PR near the surface offer a direct check on the attenuation correction procedure used in the PR algorithm. In addition to the attenuation correction, accurate radar calibration is the key to ensure reliable estimates of hydrometeor parameters. Although a variety of approaches can be used to address this issue, such as the internal calibration from which satellite instrument data have been used to assess the stability of the transmitter and receiver (Kawanishi et al. 2000), the most important type of external calibration is perhaps the comparisons of the PR-derived radar reflectivities with the estimates of the same quantities made with well-calibrated ground-based radars (Anagnostou et al. 2001; Schumacher and Houze 2000; Bolen and Chandrasekar 2000; Liao et al. 2001). Near the top of stratiform storms where dry snow is almost exclusively present, the TRMM PR returns are nearly attenuation free. Thus, the comparisons between the PR and the 
unattenuated ground-based radar returns at the storm top provide a means to evaluate the radar calibration. The aim of the present study is to check the PR calibration, evaluate its attenuation algorithms, and assess its accuracy for estimates of rainfall rate through comparisons of the PR 10-year data record over the Melbourne radar site.

To validate satellite-based measurements against ground data (regarded as the truth), an immediate challenge faced is to merge and co-locate the data that are acquired from different instruments on different platforms. Satellite data are usually registered in the global coordinate system in terms of longitude and latitude while the ground measurements are given in local coordinates, such as polar and Cartesian coordinates. As a result of the different viewing geometries from space and ground and also from the different coordinate systems adopted for the data sets, one of the critical steps for comparisons of the PR to ground radar is to accurately resample data from space-borne and ground-based measurements onto a common grid. This requires establishing consistent coordinate transformations from the global to the local coordinates when considering the effect of the earth Vcurvature. With this in mind, our first task is to develop an accurate technique that is designed to transform the data sets taken from multiple sensors on different platforms to a fixed coordinate system so that the comparisons of the data can be made on a pixel level.

In this study the ground-based radar measurements are taken from the S-band WSR-88D radar for the period from January of 1998 to February of 2007 for the overpasses of TRMM satellite over the Melbourne, Florida site during times when significant precipitation was present in the overlap region of the PR and WSR-88D. The data are provided by the TRMM Ground Validation (GV) program that has been responsible for processing ground-based measurements from the primary GV sites (Kwajalein Atoll, Republic of the Marshall Islands; Melbourne, 
Florida; Houston, Texas; and Darwin, Australia), which consist primarily of an operational weather radar and rain gauge networks (Wolff et al. 2005). TRMM science data are provided by the TRMM Science Data and Information System (TSDIS) (http://tsdis.gsfc.nasa.gov/tsdis/tsdis.html), and are publicly available from the Goddard Distributed Active Archive Center (GES DISC DAAC) (http://daac.gsfc.nasa.gov/data/datapool/TRMM/index.html).

The paper is organized as follows: a description of the data gridding and registration is given in Section 2; comparisons of the radar reflectivity factors between the PR and WSR are shown in Section 3 followed by the comparisons of rainfall rates in Section 4 . Section 5 provides a summary of the work.

\section{Data Registration}

Spaceborne and ground-based measurements usually adopt different coordinate systems. For example, TRMM PR data are given as functions of latitude, longitude and height in the earth coordinate system, while WSR-88D ground radar uses a Cartesian coordinate system in which the $\mathrm{x}$-axis is directed along the east, the $\mathrm{y}$-axis to the north, and the $\mathrm{z}$-axis perpendicular to the local surface. Therefore, one of the crucial issues for validation of the TRMM PR products using ground-based radar measurements is to register the data in a common coordinate system. This can be done by transforming from one coordinate system to the other. In this study, we will map satellite data onto the local Cartesian coordinates in order to co-locate the spaceborne and ground data sets. What follows is a detailed description of this transformation.

It is sufficiently accurate to model the earth as a sphere with radius, $R$, equal to $6.3712 \times 10^{3}$ km. In Fig.1, the Cartesian coordinates $\mathrm{O}-\mathrm{XYZ}$ are chosen such that the origin is at the center of 
the earth, and the latitude, $\varphi$, and longitude, $\lambda \square \square \mathrm{RI} \square \mathrm{D} \square \mathrm{SRLQW} \square 3 \square \mathrm{RQ} \square \mathrm{WKH} \square \mathrm{HDUWK} \| \mathrm{V} \square \mathrm{VXUIDFH} \square$ respectively, as the angle between $\mathrm{OP}$ and the $\mathrm{XY}$ plane and the angle between the projection of $\mathrm{OP}$ onto the $\mathrm{XY}$ plane and $\mathrm{X}$-axis. The origin of the o-xyz coordinate system where the ground radar is located, is on the earth surface with $\mathrm{x}$ (East) and $\mathrm{y}$ (North) axes located on the tangent plane and the z-axis perpendicular to the plane. Let $\varphi_{0}$ and $\lambda_{0}$ be the latitude and longitude of the origin of o-xyz (point $\mathrm{o}$ ). Transformation of a point $\mathrm{P}$ in the coordinates of latitude and longitude $(\varphi, \lambda)$ to the o-xyz system is equivalent to expressing the projections of the vector $\overrightarrow{O P}$ in the oxyz coordinates. This can be done by expressing the unit vectors along the $\mathrm{x}$ and $\mathrm{y}$ axes, denoted as $\ddot{\mathbb{E}}$ and $\ddot{\mathscr{Q}}$, in the $\mathrm{O}-\mathrm{XYZ}$ system. With the coordinate systems as chosen, a translation of a point at longitude $\lambda_{0}$ to $\lambda_{0}+\Delta \lambda$ corresponds to a change along the $\mathrm{x}$-axis from the origin to point A. Similarly, a translation of a point from latitude $\varphi_{0}$ to $\varphi_{0}+\Delta \varphi$ corresponds to a shift along the $y$-axis from the origin to point $B$. It is not difficult to show that $\ddot{\emptyset}$ and $\ddot{\Theta}$ can be approximated by

$$
\ddot{\mathrm{O}}=\frac{\overrightarrow{O A}}{|\overrightarrow{O A}|} \text { and } \ddot{\mathrm{O}}=\frac{\overrightarrow{O B}}{|\overrightarrow{O B}|} \text {, }
$$

where

$$
\begin{aligned}
& \overrightarrow{O A}=\overrightarrow{O A}-\overrightarrow{O o} \\
& \overrightarrow{O B}=\overrightarrow{O B}-\overrightarrow{O o} \\
& \overrightarrow{O A}=\left(R \sin \left(\pi / 2-\varphi_{0}\right) \cos \left(\lambda_{0}+\Delta \lambda\right), R \sin \left(\pi / 2-\varphi_{0}\right) \sin \left(\lambda_{0}+\Delta \lambda\right), R \cos \left(\pi / 2-\varphi_{0}\right)\right) \\
& \overrightarrow{O B}=\left(R \sin \left(\pi / 2-\varphi_{0}-\Delta \varphi\right) \cos \left(\lambda_{0}\right), R \sin \left(\pi / 2-\varphi_{0}-\Delta \varphi\right) \sin \left(\lambda_{0}\right), R \cos \left(\pi / 2-\varphi_{0}-\Delta \varphi\right)\right) \\
& \overrightarrow{O o}=\left(R \sin \left(\pi / 2-\varphi_{0}\right) \cos \left(\lambda_{0}\right), R \sin \left(\pi / 2-\varphi_{0}\right) \sin \left(\lambda_{0}\right), R \cos \left(\pi / 2-\varphi_{0}\right)\right)
\end{aligned}
$$

The arrows in the above equations denote vectors while the absolute values denote distances. From the above expressions for $\ddot{\text { Eand }} \ddot{\varrho}$, the coordinates $(\mathrm{x}, \mathrm{y})$ of $\mathrm{P}$ in the o-xyz system can be found from the following equations: 


$$
x=\overrightarrow{O P} \cdot \ddot{E} \text { and } y=\overrightarrow{O P} \cdot \ddot{\mathscr{Q}}
$$

where

$$
\overrightarrow{O P}=(R \sin (\pi / 2-\varphi) \cos (\lambda), R \sin (\pi / 2-\varphi) \sin (\lambda), R \cos (\pi / 2-\varphi))
$$

Having established coordinate relationships between satellite and ground measurements through (1)-(4), the next step is to resample the data that have different spatial sample volumes. During the TRMM pre-boost phase, prior to August 2001, the TRMM PR near-nadir field of view had horizontal and vertical resolutions of $4.3 \mathrm{~km}$ and $0.25 \mathrm{~km}$, respectively (Kozu et al. 2001). After the boost of the satellite from $350 \mathrm{~km}$ to $402.5 \mathrm{~km}$, the horizontal resolution increased to nearly $5 \mathrm{~km}$. The resolution volume of the WSR-88D ground-based radar depends strongly on range but the data are typically interpolated to a $1.5 \mathrm{~km}$ resolution along the vertical and a $2 \mathrm{~km}$ resolution in the horizontal (Wolff et al. 2005). Nearest neighbor and Delaunay triangulation interpolations are among the most common approaches that are used to estimate the values of a function over a rectangular grid from a collection of irregularly spaced data points (Watson 1992). Although the nearest neighbor interpolation is fast in that it reconstructs the function at each point on a regular grid by taking the value of the nearest sampled point, the procedure results in a piecewise constant function which will be discontinuous unless the function itself is constant. In the present study, we will use Delaunay triangulation algorithm that is widely recognized as an accurate gridding method. Its computational routine is available from the IDL graphical software package (www.ittvis.com).

In addition to taking the measurements along the satellite flight track, the TRMM PR also performs a cross-track scan from $-17^{0}$ to $17^{0}$ with respect to the nadir. For each angle bin (corresponding to a fixed scan angle) the geolocations of the PR data are given only at the earth ellipsoid. This implies that the latitude and longitude of a point at a height $\mathrm{h}$ along a fixed 
incidence angle, as shown in Fig.2, are shifted by the small distances $\Delta x$ and $\Delta y$ with respect to the geolocation at the earth ellipsoid. Although the distances $(\Delta x, \Delta y)$ are negligible for ranges close to the surface, corrections are necessary for points at higher altitudes. For example, the offset for a point at a height of $9 \mathrm{~km}$ can be as large as $2.75 \mathrm{~km}$ for the farthest off-nadir bins $\left( \pm 17^{0}\right)$. A schematic diagram is given in Fig.2 showing the geometry for the correction of the offsets ( $\Delta \mathrm{x}$ and $\Delta \mathrm{y}$ ) at a height of $\mathrm{h}$ for off-nadir incidence. Using the same notation as above with o-xyz being the local (ground radar) coordinate system, the point $\mathrm{O}^{\prime}\left(\mathrm{x}_{0}, \mathrm{y}_{0}\right)$ is defined as the intersection of the nadir-directed vector onto the $x-y$ plane and the point $P\left(x^{\prime}, y^{\prime}\right)$ to the intersection of the off-nadir incidence vector at a angle of $\theta$ with the $x-y$ plane. The point $R(x, y)$ is the projection of the point along the $\theta$-angle bin at height $h$ onto the $x$-y plane. It is not difficult to show that the offsets of $\Delta x$ and $\Delta y$ can be expressed by the following equations:

$$
x=x^{\prime}+\Delta x \text { and } y=y^{\prime}+\Delta y,
$$

where

$$
\begin{aligned}
& \Delta x=h \tan \theta \frac{x^{\prime}-x_{0}}{\sqrt{\left(x^{\prime}-x_{0}\right)^{2}+\left(y^{\prime}-y_{0}\right)^{2}}} \\
& \Delta y=h \tan \theta \frac{y^{\prime}-y_{0}}{\sqrt{\left(x^{\prime}-x_{0}\right)^{2}+\left(y^{\prime}-y_{0}\right)^{2}}} .
\end{aligned}
$$

Shown in Fig. 3 is an example of comparisons between the PR and WSR-88D measurements on 9 March 1998 at Melbourne, Florida, by use of the registration techniques described above. The left panels give maps of the reflectivities (in dBZ) of the PR (top) and WSR-88D (bottom) at a height of $3 \mathrm{~km}$ in the scan area of $300 \times 300 \mathrm{~km}^{2}$ centered at the WSR-88D site. The right panels display the vertical profiles of the PR reflectivities (top) and WSR-88D reflectivities (bottom) along the path $\mathrm{AB}$ marked on the maps shown in the left panels. In Fig.3, the original resolutions 
are retained for the PR and WSR data sets: a grid of $4 \times 4 \times 0.25 \mathrm{~km}^{3}$ for the PR and $2 \times 2 \times 1.5 \mathrm{~km}^{3}$ for the WSR. Examination of the images shows that the storm structure and magnitudes of radar reflectivities are similar. Note that the PR yields more detailed structure in the vertical than does the ground radar because of its relatively high range resolution and near-nadir incidence. Considering the PR and WSR-88D data resolutions, a common grid element of $4 \times 4 \times 1.5 \mathrm{~km}^{3}$ is chosen in this study for the comparisons between the PR and WSR-88D data.

\section{Comparisons of Radar Reflectivity Factor}

The primary reasons for comparing the radar reflectivity factors from spaceborne and ground-based radars are two-fold: the first is to determine the relative calibration accuracy of the radars and the second to assess the performance of the attenuation correction procedures used for estimates of rain. Near the top of stratiform storm where dry snow is almost exclusively present, the radar returns of the TRMM PR are largely unaffected by attenuation. Comparisons of the unattenuated radar reflectivities from the ground-based WSR to the attenuation-corrected radar reflectivities from the PR in the range near the surface offer a direct check on the attenuation correction procedure used in the PR algorithm. Because the PR and WSR operate at the different wavelengths, as a result of non-Rayleigh scattering at $\mathrm{Ku}$ band, differences in the radar reflectivity factors occur when relatively large particles are present. This is true for both snow and rain particles. To account for this effect, a simulation of the radar reflectivity factors is needed at $\mathrm{S}$ and $\mathrm{Ku}$ bands to account for reflectivity differences in terms of the characteristic parameters of the particle size distribution. In the following we will start with the computations of the differences of radar reflectivity factors between $\mathrm{S}$ and $\mathrm{Ku}$ bands followed by the instantaneous and statistical comparisons of radar reflectivities. 


\subsection{Differences of Radar Reflectivity factors between $S$ and $K u$ Bands}

The effective radar reflectivity factor $Z_{\mathrm{e}}$, which is related to the particle size distribution $N(D)$ and the backscattering cross section $\sigma_{b}(D, \lambda)$ of the hydrometeors at wavelength $\lambda$, is given as

$$
Z_{e}=\frac{\lambda^{4}}{\pi^{5}\left|K_{w}\right|^{2}} \int_{0}^{\infty} N(D) \sigma_{b}(D, \lambda) d D
$$

where the $K_{w}$, the dielectric factor, is used to designate $\left(\mathrm{m}^{2}-1\right) /\left(\mathrm{m}^{2}+2\right)$, where $m$ is the complex refractive index of water. By convention, $\left|\mathrm{K}_{\mathrm{w}}\right|^{2}$ is taken to be 0.93 (Battan 1973). $\sigma_{\mathrm{b}}(\mathrm{D}, \lambda)$ can be computed for spheres by Mie theory and for non-spheres (spheroids) by the T-matrix method (Barber and Hill, 1990). The particle size distributions can be conveniently described by the gamma distribution (Braham 1990; Gorgucci et al. 2000, 2002; Bringi 2002), and is expressed as

$$
N(D)=N_{0} D^{\mu} \exp \left[-\left.(3.67+\mu) \frac{D}{D_{0}}\right|_{1},\right.
$$

where $\mathrm{N}_{0}$ is a parameter related to the hydrometeor number density, $\mathrm{D}$ the particle diameter, $\mathrm{D}_{0}$ the median volume diameter of the particle and $\mu$ the shape factor. The radar dual-frequency ratio (DFR) in $\mathrm{dB}$, describing the difference of the radar reflectivity at $\mathrm{S}$ and $\mathrm{Ku}$ bands, is defined as

$$
D F R=10 \log \left(Z_{S} / Z_{K u}\right)
$$

where $Z_{S}$ and $Z_{K u}$ are the radar reflectivity factors at $S$ and $K u$ bands. For fixed $\mu$, the DFR is a function only of $D_{0}$.

To understand magnitudes of the DFR with respect to the characteristic parameters of hydrometeors, Fig.4 displays some of the computational results of DFR for snow in terms of $D_{0}$ at several snow densities for an exponential snow size distribution (i.e., $\mu=0$ in (8)), which is 
consistent with many observational results (Braham 1990; Liao et al. 2005). The snowflake is treated as a sphere that approximates the mean of the scattering results from an ensemble of the equi-volume non-spherical particles with random orientations. As can be seen in Fig.4, the DFR does not exceed $1 \mathrm{~dB}$ if $\mathrm{D}_{0}$ is less than $2 \mathrm{~mm}$, and is less than $0.5 \mathrm{~dB}$ for $\mathrm{D}_{0}$ smaller than $1 \mathrm{~mm}$. The DFR- $\mathrm{D}_{0}$ relations are insensitive to the snow density for small $\mathrm{D}_{0}$ and only slightly dependent on the snow density for the large $\mathrm{D}_{0}$.

Assuming the Beard and Chuang (1987) shape-size relationship for raindrops, the results of $\mathrm{DFR}$ at $\mathrm{S}$ and $\mathrm{Ku}$ bands for rain are computed as a function of $\mathrm{D}_{0}$ for several shape factors of gamma drop-size distribution, as shown in Fig.5. For these computations the symmetry axes of the raindrops that are assumed to be oblate spheroids without canting are aligned along the vertical. The PR is assumed to view the rain along the nadir direction while the WSR-88D is assumed to view the rain along the horizontal direction. For the smaller $D_{0}$, the DFR is very small, and is nearly invariant with increases in $\mathrm{D}_{0}$ because of dominance of Rayleigh scattering at both wavelengths. With an increase in $D_{0}$, the DFR becomes negative, i.e., the reflectivity at $\mathrm{Ku}$ band is larger than that at $\mathrm{S}$ band as a result of non-Rayleigh scattering effects at Ku-band.

\section{$\underline{3.2 \text { Instantaneous and Statistical Comparisons }}$}

As mentioned earlier, the TRMM satellite has been in orbit for over a decade, and a large amount of the data has been collected under various storm conditions. The ground-based WSR88D radar located at Melbourne near the Atlantic coast in central Florida has served as one of the TRMM Ground Validation (GV) sites. Over the 10 years of TRMM operation, data from several hundred rain events have been collected during TRMM PR overflights. To include as many TRMM overpass events as possible and to ensure the reliability of the data, the criteria for the selection of the TRMM overpass data are to require that the rainy area within the WSR scan be at 
least 5\% and to require that the closest distance between the PR satellite ground track at nadir and the WSR site be within $200 \mathrm{~km}$. Using the TRMM GV standard product 2A52 that provides the TRMM PR flight information and the percentage of rain area in the WSR scan, 210 overpasses are found over the Melbourne site for the period from January of 1998 to February of 2007 after filtering a few overpasses that have no more than 10 rainy pixels within the intersection area of the PR and WSR. The TRMM products $2 \mathrm{~A} 25$ (version 6) and GV product 2A55 (version 5) are used to extract the radar reflectivities for the PR and WSR, respectively. As noted earlier, the PR data (2A25) are registered on the earth ellipsoid with the footprint of about $4 \times 4 \mathrm{~km}^{2}$ and range resolution of $0.25 \mathrm{~km}$ for the normal sampling. The $2 \mathrm{~A} 55$ product provides $3-$ dimentional gridded data of the radar reflectivity for WSR-88D with spatial resolution of $2 \mathrm{~km} \times$ $2 \mathrm{~km} \times 1.5 \mathrm{~km}$ in the $\mathrm{x}, \mathrm{y}$ and $\mathrm{z}$ directions over a maximum range of $150 \mathrm{~km}$ (relative to radar). In almost all cases, the WSR-88D experiences negligible attenuation in rain, and therefore the correction for its attenuation is not made in this study. To resample the data of radar reflectivity from PR and WSR-88D onto the common grid $\left(4 \times 4 \times 1.5 \mathrm{~km}^{3}\right)$, the procedures for averaging and interpolating the radar reflectivity are performed in the linear scale (i.e., $\mathrm{Z}$ in units of $\mathrm{mm}^{6} / \mathrm{m}^{3}$ ).

Shown in Fig.6 are the scatter plots (top) of instantaneous comparisons of the radar reflectivities between the PR and WSR at a height of $7.5 \mathrm{~km}$ along with the corresponding probability density functions, PDF, (bottom). The results are grouped into the cases of stratiform and convective storms as well as all rain types. The classification of storm types shown in the plots is based exclusively on the PR observations, which follows TRMM 2A23 product. In 2A23 each PR range profile is classified into either stratiform, convective or ${ }^{3}$ other ${ }^{\prime}$ ( (Awaka et al. 1998). Information is also given with respect to the accuracy of the classification based in part on the vertical and horizontal structure of the storm and whether these analyses lead to the same 
classification. Since there is very small portion (less 1\%) of the data in the category of the

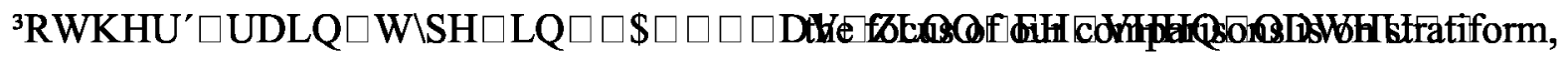
convective and all-rain (stratiform, convective, and other) categories. The minimum radar reflectivity chosen for the comparisons is $18 \mathrm{dBZ}$ (the nominal sensitivity of the PR) for both radars even though the WSR-88D has much higher sensitivity (better than $-15 \mathrm{dBZ}$ over the entire scan range). At the height of $7.5 \mathrm{~km}$ (near the storm top), the hydrometeors are primarily dry snow. This is always the case in stratiform storms where the snow and rain are clearly separated by the melting layer or bright band. The dashed lines in the top panels of Fig. 6 are the one-to-one lines while the solid lines describe the radar reflectivities simulated by use of the exponential snowflake size distribution reported by Gunn and Marshall (1958) when assuming the mean snow density of $0.3 \mathrm{~g} / \mathrm{cm}^{3}$. As expected from the results of Fig.4, the simulated radar reflectivities coincide with the one-to-one lines in the range where the reflectivity is relatively small (corresponding to small $\mathrm{D}_{0}$ ), and then gradually deviate from the one-to-one line as the reflectivity increases. This is to some extent consistent with the trend shown in the scatter plots of Fig.6. In addition, good correlation coefficients are found for the convective and all-rain categories with the value of 0.81 . The relatively poor correlation $(0.58)$ for stratiform rain is caused by the facts that the majority of the data are near the PR noise floor level (18 dBZ) and vary within a small dynamic range of about $8 \mathrm{~dB}$. The PDFs shown in the lower panels of Fig. 6 are useful in that, in contrast to the pixel level comparisons, the PDF results are much less sensitive to the uncertainties resulting from mismatches of the data and other intrinsic data registration errors. For reference the PR measured (uncorrected) radar reflectivity is also shown in the plots. As can be seen, near the storm top the measured and corrected PR reflectivities are 
virtually the same since the PR attenuation is negligibly small in snow. Table 1 lists the mean values of the radar reflectivities for stratiform, convective and all-rain categories.

The quantity $<\mathrm{PR}>^{*}$ is the expected mean $\mathrm{PR}$ reflectivity as estimated from the mean values of the WSR (<WSR>) under the assumption of the Gunn and Marshall distribution (1958). The relationship between $<\mathrm{PR}>*$ and $<\mathrm{WSR}>$ is depicted by the solid lines in Fig.6. For the snow size distribution described by Gunn and Marshall (1958), the particle size distribution is specified for each snowfall rate, which, in turn, can be used to compute $Z_{\mathrm{Ku}}$ and $Z_{\mathrm{S}}$. Thus the functional relation (solid curves) between $\mathrm{Z}_{\mathrm{Ku}}$ and $\mathrm{Z}_{\mathrm{S}}$ is obtained by varying the snowfall rate. The degree of the agreement between $<\mathrm{PR}>$ (mean reflectivities from actual $\mathrm{PR}$ data) and $<\mathrm{PR}>^{*}$ reflects the accuracy of the relative radar calibration. It can be seen that the PR, in general, agrees well with the $<\mathrm{PR}>^{*}$ and yields only a small positive bias of about $0.8 \mathrm{~dB}$ for all of the rain types. In view of the uncertainties associated with the assumption of snow size distribution and snow density that are used for computation of the relationship of radar reflectivities and the intrinsic errors caused by possible mismatch of scattering volumes in time and space between the satellite and ground-based measurements, an agreement within $1 \mathrm{~dB}$ indicates that the PR is relatively well calibrated.

To assess the PR attenuation algorithms, similar sets of comparisons at the height of $1.5 \mathrm{~km}$ above the surface are shown in Fig.7. Near the surface the precipitation is almost always rain. The simulated relationship (solid lines) of the radar reflectivity factors between $\mathrm{S}$ and $\mathrm{Ku}$ bands are computed using the Marshall-Palmer raindrop size distribution (1948). The particle shape is assumed to be an oblate spheroid that follows Beard-Chuang shape-size relation (1987). As shown in Fig.7, deviations of the simulated relations from the one-to-one line (dashed line) are almost indistinguishable when the radar reflectivity factors are less than $35 \mathrm{dBZ}$. The results of 
the instantaneous comparisons (scatter plots) show strong correlation for each storm type. Shown in the lower panels of Fig.7 are the results of PDF that are derived from the radar reflectivities given in the top panels. The PR measured reflectivity, denoted as $\mathrm{PR}_{\mathrm{m}}$, is also included in the

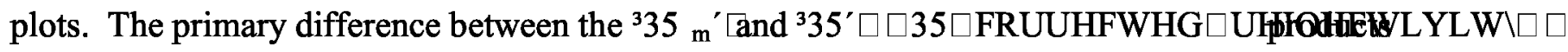
is that the latter has been corrected for attenuation. As expected, only a small correction is made under stratiform rain conditions where the rain is generally light. In contrast, for convective rain, a large attenuation correction is made as indicated by the significant shift of the PDF from ${ }^{3} 35 \mathrm{~m}^{\prime} \square$ (no attenuation correction) WR $\square^{33} 3$ atttenuation-corrected). The results reveal that the PDF of the PR radar reflectivities after attenuation correction tend to agree with those of the WSR-88D, indicating that the attenuation algorithm is generally effective. The mean radar reflectivities are summarized in Table 2 . The quantity $\langle\mathrm{PR}\rangle^{*}$ corresponds to the results of the WSR at the values of $<$ WSR $>$ from the simulated radar reflectivities (solid lines). The straight differences between $<\mathrm{PR}>$ and $<\mathrm{PR}>^{*}$, a measure of the effectiveness of the PR attenuation correction algorithms, are $1,-0.8$ and $-0.4 \mathrm{~dB}$ for stratiform, convective and all the rain cases, respectively. However, if an account is made for the $0.8 \mathrm{~dB}$ offset in connection with the PR relative calibration discussed previously, then the values above are changed to $0.2,-1.6$ and $-1.2 \mathrm{~dB}$.

Another statistical comparison is obtained by taking the means of the radar reflectivities for each overpass on a conditional basis, i.e., the pixels are used only if both PR and WSR exceed the pre-defined threshold ( $18 \mathrm{~dB})$. Figure 8 shows the mean of the PR-derived radar reflectivity factors versus the mean of the WSR radar reflectivity factors at a height of $3 \mathrm{~km}$ from the 210 TRMM overpasses for the period 1998-2007. Each data points represent an overpass event, where the size of the data point is proportional to the number of pixels in the overlap region for which both PR and WSR exceed $18 \mathrm{dBZ}$. The asterisk on the plot represents the weighted 
means $(<\mathrm{PR}>=29.68 \mathrm{dBZ}$ and $<\mathrm{WSR}>=28.98 \mathrm{dBZ})$. As in Fig.7, the simulated results, i.e., the relation between the PR and GV when a Marshall-Palmer size distribution is assumed, are shown by the solid line in Fig. 8 . The simulated PR mean reflectivity, $<\mathrm{PR}>^{*}$, which corresponds to the WSR mean value of $28.98 \mathrm{dBZ}$, is equal to $29.43 \mathrm{dBZ}$. Thus, the quantity of $<\mathrm{PR}>-<\mathrm{PR}>*$ is $0.25 \mathrm{~dB}$, and becomes $-0.55 \mathrm{~dB}$ if an offset $(0.8 \mathrm{~dB})$ associated with the PR relative calibration is taken into account. This represents only $2 \%$ uncertainty with respect to the WSR results. Once again, it shows that the PR radar reflectivity after attenuation correction compares well with the ground-based radar.

\section{Comparisons of Rain Rate}

The ultimate goal of the TRMM is to map rain in the tropics. Because of differences of wavelengths and geometries in viewing the rain from space and ground, the algorithms for estimating rain are by no means the same. For the TRMM ground validation (GV) radars constant Z-R relationships are employed throughout the radar volume scans (Wolff et al. 2005), which are adjusted monthly according to the probability density function (PDF) of the rain rates measured from the surface gauge network by use of the Window Probability Matching Method (WPMM) (Rosenfeld et al. 1994). The PR, on the other hand, does not use a single Z-R relation since the Z-R relation changes from one location to other in accordance with the $\alpha$-adjustment method (Iguchi et al. 2000).

The comparisons of rain in the overlap region between the satellite overpass and ground radar scan volume can be conducted in two ways. One is on a conditional basis in which the instantaneous rain rates are compared only at those pixels where both the space and ground radar detect the rain. Another way to present the data is to compare the instantaneous area-average rain rate, which is defined as the rain rate averaged over the area of intersection of the space and 
ground radar scans. As a consequence of this definition, the area-average rain rate can be estimated independently for the space and ground radars since there is no requirement that rain in individual pixels must be detected by both radars.

\subsection{Conditional Rain Comparisons}

Figure 9 depicts instantaneous comparisons of the scatter plots (top) of surface rain rate and the corresponding PDF (bottom) between the PR and Melbourne WSR-88D from 210 TRMM overpasses for the period from 1998 to 2007. Note that the PR data are taken from the ${ }^{3} \mathrm{QHDU}$ VXUIDFH $\square$ UDLQIPOACLADWMMM 2A25, which is defined as the lowest point in the clutterfree range profile. The WSR rainfall rates are provided by $2 \mathrm{~A} 53$ product that derives the surface rainfall rate by use of $1.5 \mathrm{~km}$ and $3 \mathrm{~km}$ CAPPI (Constant Altitude Plan Position Indicator) data for near and far radar ranges, respectively. Because of these differences, the PR and WSR matching pixels are not always at the same height. This offset in height varies from pixel to pixel depending on location of the PR swath relative to the WSR scan area. In spite of these registration errors, an analysis of the results illustrated in Fig.9 shows that there is fairly good agreement between the PR- and WSR-derived rain rates for the case of stratiform rain. This is reflected by the reasonably good correlation and agreement in the PDFs. The mean rain rates, given in the brackets in Fig.9, are 4.33 and $3.99 \mathrm{~mm} / \mathrm{h}$ for PR and WSR, respectively, representing less than $9 \%$ difference. On the other hand, for convective rain the PR tends to overestimate light rain, and underestimate moderate to heavy rain in comparison with the WSR data. The mean rainfall rates for the convective storm are $12.49 \mathrm{~mm} / \mathrm{h}$ and $15.39 \mathrm{~mm} / \mathrm{h}$ for the PR and WSR, respectively, reflecting a difference of about $19 \%$. It is worth noting that the $19 \%$ underestimate of the PR-derived rain is an average result and that there is some cancellation from the positive and negative biases that occur, respectively, in light and heavy rain. As such, the 
actual estimates of the rainfall rate from the PR are expected to be worse than $19 \%$ in some ranges, such as in heavy rain. It is also noted that a negative bias in the PR estimates for convective rain is consistent with the results of the reflectivity comparisons in which it was found that the PR is about $1.6 \mathrm{~dB}$ smaller than the WSR. However, when all the rain cases are considered, the PR agrees well with the WSR with the difference in the means of about $8 \%$. It should be mentioned that the minimum rain rate used for our rain comparisons is chosen as 0.5 $\mathrm{mm} / \mathrm{h}$ for both radars, which is usually considered as the PR minimum detectable rain. In Fig.9 the stratiform rain $(47,277$ pixels $)$ is about $71 \%$ of the total rain $(66,271$ pixels $)$ while the convective $(18,763$ pixels) is around $28 \%$.

Shown in Fig. 10 are the means of the PR-derived rain rate versus the means of the WSRderived rain rate for the 210 overpasses over Melbourne of Florida from 1998-2007. As before, each data point represents an overpass event. The size of each data point is proportional to the number of cells in the overlap region for which both the PR- and WSR-derived rain rates are greater than $0.5 \mathrm{~mm} / \mathrm{h}$ (PR threshold). The asterisk represents the weighted means of the data sets and corresponds to rain rates of $6.63 \mathrm{~mm} / \mathrm{h}$ and $7.22 \mathrm{~mm} / \mathrm{h}$ for PR and WSR, respectively. It is worth pointing out that the results of the mean rain rates given in Fig.10 are identical to those obtained from Fig.9 for all the rain cases because the mean is a linear operator. From Fig.10, it is found that the PR and WSR rain data are generally highly correlated except for a few outliers that are associated with the TRMM overpasses with highly non-uniform spatial data.

\subsection{Unconditional Rain Comparisons}

As mentioned earlier, comparison of the area-averaged rain rate can be considered unconditional because the constraint used for the conditional rain comparison in which the pixels 
are used only if both PR and WSR detect rain, is no longer required. For one satellite overpass, the area-averaged rain, $R_{\text {areaAvg, }}$ is defined as

$$
R_{\text {areaAvg }}=\frac{\sum_{n=1}^{N} R_{n}\left(R \geq R_{\min }\right) \Delta A_{n}}{\sum_{n=1}^{N} \Delta A_{n}},
$$

where $R_{n}$ and $\Delta A_{n}$ are respectively the rain rate and footprint or horizontal resolution area at the nth pixel within the intersection area of the PR and WSR scans, and $\mathrm{N}$ is the total number of pixels. The summation in (10) is carried out only over the pixels in which the rain rate is greater than a pre-defined threshold, $R_{\min }$. Because $\Delta A_{n}$ is uniform for the both PR $\left(\sim 4 \times 4 \mathrm{~km}^{2}\right)$ and WSR $\left(2 \times 2 \mathrm{~km}^{2}\right)$ and because the PR threshold is $0.5 \mathrm{~mm} / \mathrm{h}$, above equation can be simplified to:

$$
R_{\text {areaAvg }}=\frac{\sum_{n=1}^{N} R_{n}(R \geq 0.5)}{N}
$$

Using (11) the area-averaged rain rates of the PR and WSR can be derived independently and can be done without resampling the data into the common grids. The only remaining task is to define the PR and WSR intersection area for each overpass. Figure 11 illustrates an example of the PR-WSR intersection area, which is given by the circular lightly-shaded area with storms superimposed on it. The shaded region (lightly and heavily) represents the PR swath on the ground. Note that a small area surrounding the WSR that corresponds to the WSR blind (nosignal) region is excluded from the intersection area.

Shown in Fig.12 are the scatter plots of the PR and WSR area-averaged rain rate obtained from the 210 TRMM overpasses from the 10-year record over Melbourne. Unlike conditional rain comparisons in which the mean of the rain rate is derived by weighting the individual means associated with each TRMM overpass by the number of rain pixels, the mean of area-averaged 
rain rates are obtained by weighting the means of all the overpasses equally. As seen in Fig.12, a strong correlation is found between the PR and WSR data with their means equal to $0.74 \mathrm{~mm} / \mathrm{h}$ and $0.80 \mathrm{~mm} / \mathrm{h}$ for the PR and WSR, respectively. The negative bias $(0.06 \mathrm{~mm} / \mathrm{h})$ of the PR, relative to the WSR, represents an $8 \%$ difference. These results are in general agreement with those from the conditional rain comparisons. In principle, the comparison of the area-averaged rain should be less affected by the spatial and temporal offsets or mismatches in the registrations of the PR and WSR data than in the case of conditional rain comparison. An agreement between the conditional and unconditional rain comparisons suggests that the registration techniques developed for the PR and ground-radar comparisons are accurate.

\section{Summary}

A rigorous procedure has been developed for accurate registration of the space and ground radar measurements. By applying this technique, validation of the TRMM PR measurements and estimates of rain rate can be made through comparisons with the well-calibrated non-attenuated ground-based WSR-88D radar data. Over the span of 10 years (1998-2007) 210 TRMM overpasses, in which the significant rain was present, are found over Melbourne, Florida. With this large amount of data the PR calibration has been checked in the snow region (near the storm top) by comparing the PR reflectivity factors to those measured from the WSR. This is based on the principle that attenuation of the PR is negligible in snow, and on the assumption that the PR signal undergoes no attenuation prior to the snow. Near the top of storm the instantaneous comparisons show reasonably good correlations between the PR and WSR radar reflectivities in snow. Moreover, an analysis of the statistical comparisons indicates that the PR exhibits only a small bias $(0.8 \mathrm{~dB})$ relative to the WSR. In view of all the possible uncertainties including the model of the particle size distribution that is used to establish the baseline for the comparisons of 
the radar reflectivities at $\mathrm{Ku}$ and $\mathrm{S}$ bands as well as temporal offsets in collecting data between the PR and WSR in which the WSR takes approximately 6 minutes to complete a volume scan while the TRMM satellite overflies the GV site on the order of seconds, it is reasonable to conclude that the PR is well calibrated and that the calibration has held steady over the 10-year period.

The PR attenuation algorithm has been evaluated by comparing PR attenuation-corrected radar reflectivities to the WSR measurements near the surface. The PR attenuation-corrected reflectivities are highly correlated with the WSR measurements for stratiform and convective storms as well as the combined rain. It is found that, after accounting for a difference of $0.8 \mathrm{~dB}$ between the PR and WSR at the storm top, there is only a $0.2 \mathrm{~dB}$ offset between the PR mean radar reflectivity and the expected PR reflectivity computed from the WSR mean reflectivity based on the Marshall-Palmer raindrop size distribution. For the convective rain, however, the PR underestimates the path attenuation on average by $1.6 \mathrm{~dB}$. The combined effect of a positive $0.2 \mathrm{~dB}$ offset for the stratiform rain ( $71 \%$ of the rain occurrences) and a negative $1.6 \mathrm{~dB}$ offset for convective rain ( $28 \%$ of the rain occurrences) yields an underestimate of path attenuation by the PR of $0.4 \mathrm{~dB}$ for all events from 210 overpasses.

Validation of the PR rain estimates is made through comparisons to the WSR surface rain, using both conditional and unconditional statistics. Because of different methods used by the PR and the WSR the rain comparisons will not necessarily be consistent with the reflectivity comparisons. Analysis of the conditional rain comparisons reveals that the PR-derived rain is, on average, about $9 \%$ greater and $19 \%$ less than those estimated from the WSR for stratiform and convective rain, respectively. Overall, the PR underestimates the conditional mean rain rate by $8 \%$ relative to the WSR. The results of the unconditional rain comparisons, made through 
comparison of the area-averaged rain rate, show that the PR underestimates the rain by $8 \%$. This agrees with the result derived from the conditional rain comparisons. The area-averaged rain, as discussed earlier, is not sensitive to the data sampling and gridding that are crucial for the conditional rain comparisons. Agreement between the conditional and unconditional rain comparisons implies that the registration techniques described here are effective.

We conclude from our study of TRMM PR comparisons to the Melbourne radar results that the PR has a stable and accurate calibration and that the PR attenuation-correction procedure for the stratiform rain is fairly accurate and leads to reasonably good estimates of rainfall rate. Underestimates of the PR attenuation for convective rain are primarily responsible for the relatively large rain rate underestimates. It should be noted that our findings from this study are confined to the Melbourne site, and are not necessary representative of results from other regions. As variability in climate, surface background and raindrop size distributions affect PR performance, the validation task should be extended to other sites and climatological regions. It is hoped that the current study has relevance to the design of a ground validation strategy for the Global Precipitation Measuring (GPM) mission that is designed to map the precipitation globally.

\section{ACKNOWLEDGMENTS}

We wish to thank David Wolff, David Marks and Goddard Space Flight Center TRMM office for providing ground-based WSR data. This work is supported by Dr. R .Kakar of NASA +HDGTXDUWHUV $\square \quad$ XQGHU $\square \quad 1 \$ 6 \$$ TV $\square \quad$ 3UHFLSAnwhiWLKßsion 0H(BMXY grant NNH06ZDA001N-PMM. 


\section{References}

Amitai, E., J. A. Nystuen, L. Liao, R. Meneghini, and E. Morin, 2004: Uniting space, ground and underwater measurements for improved estimates of rain rate. IEEE Geoscience and Remote Sensing Letters, 1, 35-38.

Amitai, E., L. Liao, X. Llort, and R. Meneghini, 2005: Accuracy verification of spaceborne radar estimates of rain rate. Atmos. Sci. Letters., DOI: 10.1002/asl.82.

Anagnostou, M. S., C. A. Morales, and T. Dinku, 2001: The use of TRMM precipitation radar observations in determining ground radar calibration biases. J. Appl. Meteor., 39, 21982208.

Awaka, J., T. Iguchi, and K. Okamoto, 1998: Early results on rain type classification by the Tropical Rainfall Measuring Mission (TRMM) precipitation radar. Proc. 8th URSI Commission F Open Symp., Aveiro, Portugal, 143-146.

Barber, P. and S. C. Hill, 1990: Light Scattering by Particles: Computational Methods. World Scientific, Singapore, 400pp.

Battan, L. J., 1993: Radar Observations of the Atmosphere. University of Chicago Press, 324 pp.

Beard, K. V., and C. Chung, 1987: A new model for the equilibrium shape of raindrops. J. Atmos. Sci., 44, 1509-1524.

Bolen, S.M. and V. Chandrasekar. 2000. Quantitative cross validation of space-based and groundbased radar observations. J. Appl. Met. 39, 2071-2079.

Braham, R. R., 1990: Snow particle size spectra in lake effect snows. J. Appl. Meteor., 29, 200207.

Bringi, V., G. Huang, V. Chandrasekar and E. Gorgucci, 2002: A methodology for estimating the parameters of a Gamma raindrop size distribution model from polarimetric radar data: Application to a squall-line event from the TRMM/Brazil campaign. J. Oceanic and Atmos. Tech., 19, 633-645.

Gorgucci, E., G. Scarchilli, V. Chandrasekar and V. Bringi, 2000: Measurement of mean raindrop shape from polarimetric radar observations. J. Atmos. Sci., 57, 3406-3413.

Gorgucci, E., G. Scarchilli, V. Chandrasekar and V. Bringi, 2002: Estimation of raindrop size distribution parameters from polarimetric radar measurements. J. Atmos. Sci., 59, 23732384.

Gunn, K. L. S., and J.S. Marshall, 1958: The distribution with size of aggregate snowflakes. $J$. Meteor., 15, 452-461. 
Hitschfeld, W., and J. Bordan, 1954: Errors inherent in the radar measurement of rainfall at attenuating wavelengths. J. Meteor., 11, 58-67.

Iguchi, T., T. Kozu, R. Meneghini, J. Awaka and K. Okamoto, 2000: Rain-profiling algorithm for the TRMM precipitation radar. J. Appl. Meteorol., 39, 2038-2052.

Kawanishi, T., and Coauthors, 2000: TRMM precipitation radar. Adv. Space Res., 25, 969-972.

Kozu, T, and Coauthors, 2001: Development of precipitation radar onboard the Tropical Rainfall Measuring Mission (TRMM) satellite. IEEE Trans. Geosci. Remote Sens., 33, 1316-1318.

Kummerow, C., and Coauthors, 2000: The status of the Tropical Rainfall Measuring Mission (TRMM) after two years in orbit. J. Appl. Meteorol., 39, 1965-1982.

Liao, L., R. Meneghini and T. Iguchi, 2001: Comparisons of rain rate and reflectivity factor derived from the TRMM Precipitation Radar and the WSR-88D over the Melbourne, Florida, site. $J$. Atmos. Oceanic Technol., 18, 1959-1974.

Liao, L., R. Meneghini, T. Iguchi, and A. Detwiler, 2005: Use of dual-wavelength airborne radar

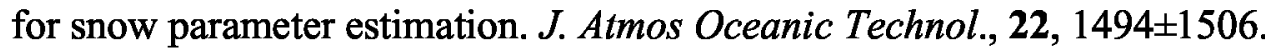

Marks, D. A., M. S. Kulie, M. Robinson, D. S. Silberstein, D. B. Wolff, B. S. Ferrier, E. Amitai, B. Fisher, J. Wang, D. Augustine, and O. Thiele, 2000: Climatological processing and product development for the TRMM ground validation program. Phys. Chem. Earth (B), 25, 871875.

Marshall, J. S., and W.M. Palmer, 1948: The distribution of raindrops with size. J. Appl. Meteor., 5, 165-166.

Meneghini, R., T. Iguchi, T. Kozu, L. Liao, K. Okamoto, J. A. Jones, and J. Kwiatkowski, 2000: Use of the surface reference technique for path attenuation estimates from TRMM precipitation radar. J. Appl. Meteor., 39, 2053-2070.

Rosenfeld, D., D. B. Wolff, and E. Amitai, 1994: The window probability matching method for rainfall measurements with radar. J. Appl. Meteor., 33, 682-693.

Simpson, J., R. F. Adler, and G. R. North, 1988: A proposed Tropical Rainfall Measuring Mission (TRMM) satellite. Bull. Amer. Meteor. Soc., 69, 278-295.

Schumacher, C., and R. A. Houze, 2000: Comparison of radar data from the TRMM satellite and Kwajalein ocean validation site. J. Appl. Meteor., 39, 2151-2164.

Watson, D. F., 1992: Contouring: A guide to the analysis and display of spatial data. Pergamon Press, $321 \mathrm{pp}$. 
Wolff, D. B., D. A. Marks, E. Amitai, D. S. Silberstein, B. L. Fisher, A. Tokay, J. Wang, and J. L. Pippitt, 2005: Ground validation for the Tropical Rainfall Measuring Mission (TRMM). $J$. Atmos. Oceanic Technol.., 22, 365-380. 
Table 1 The means of the radar reflectivity factors (in $\mathrm{dBZ}$ ) derived from the TRMM PR and WSR-88D for stratiform, convective and total rain pixels at the height of $7.5 \mathrm{~km}$ from 210 TRMM overpasses for the period 1998-2007 in the Melbourne of Florida. 1RWDWLRQV $\square_{\mathrm{m}} \mathrm{RIm} \mathrm{m}^{3} 35$

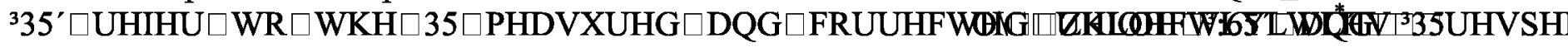
to the WSR measured and converted-to-PR-wavelength reflectivities.

\begin{tabular}{|l|c|c|c|c|}
\hline Storm Type & $<$ WSR & $<$ PR $_{\mathbf{m}}>$ & $<$ PR & $<$ PR ${ }^{*}$ \\
\hline Stratiform & 20.99 & 21.43 & 21.39 & 20.61 \\
\hline Convective & 24.35 & 24.61 & 24.59 & 23.74 \\
\hline Total & 22.59 & 22.95 & 22.92 & 22.10 \\
\hline
\end{tabular}


Table 2 The means of the radar reflectivity factors (in dBZ) derived from the TRMM PR and WSR-88D for stratiform, convective and total rain pixels at the height of $1.5 \mathrm{~km}$ from 210 TRMM overpasses for the period 1998-2007 in the Melbourne of Florida. 1RWDWLRQV ${ }_{\mathrm{m}} \mathrm{RT \Pi \Pi ^{3 } 3 5}$ 335' UHIHU $\square$ WR $\square$ WKH $\square 35 \square$ PHDVXUHG $\square$ DQG $\square$ FRUUHFWHG $\square$ UHIOHFWLYLWL"HV $\square \square$ UHVSH to the WSR measured and converted-to-PR-wavelength reflectivities.

\begin{tabular}{|l|c|c|c|c|}
\hline Storm Type & $<$ WSR $>$ & $\left\langle\right.$ PR $_{\mathbf{m}}>$ & $<$ PR $>$ & $<$ PR $>^{*}$ \\
\hline Stratiform & 26.90 & 27.44 & 28.04 & 27.06 \\
\hline Convective & 33.72 & 31.71 & 33.94 & 34.77 \\
\hline Total & 28.80 & 28.61 & 29.66 & 29.23 \\
\hline
\end{tabular}




\section{Figure Captions:}

Fig.1 Schematic diagram of the earth coordinate system in which the latitude, $\varphi$, and longitude, $\lambda$, are defined.

Fig. 2. Geometry for correction of PR offsets $(\Delta x$ and $\Delta y)$ in $x$ and $y$ axes at a height of $h$.

Fig. 3. Measurements of the PR (top) reflectivities, with attenuation correction, and the WSR-88D (bottom) reflectivities (dBZ) for the March 9, 1998 overpass. Left: CAPPI display at a height of 3 $\mathrm{km}$; right: $\mathrm{RHI}$ display along the path $\mathrm{AB}$.

Fig. 4. DFR of $\mathrm{S}(3 \mathrm{GHz})$ and $\mathrm{Ku}(13.8 \mathrm{GHz})$ bands versus the median volume diameter $\left(\mathrm{D}_{0}\right)$ of snow particles as the snow mass density $\left(\rho_{\mathrm{s}}\right)$ varies from 0.05 to $0.3 \mathrm{~g} / \mathrm{cm}^{3}$ for the case of $\mu=0$.

Fig.5 DFR of S (3 GHz) and $\mathrm{Ku}(13.8 \mathrm{GHz})$ bands versus the median volume diameter $\left(\mathrm{D}_{0}\right)$ of raindrops as the shape factor of the gamma size distribution is changed from 0 to 6 .

Fig. 6 Scatterplots of radar reflectivity factors (top panels) and their probability density functions (bottom panels) at a height of $7.5 \mathrm{~km}$ derived from 210 TRMM overpasses over Melbourne, Florida for the period 1998-2007. The solid lines (black and white) are the computational results based on the snow size distribution obtained by Gunn Marshall (1958) for a snow density of $0.3 \mathrm{~g} / \mathrm{cm}^{3}$. The results are divided into different storm types that are

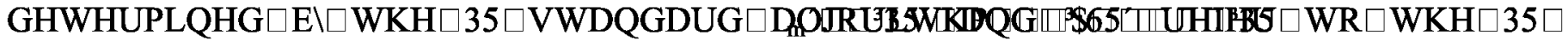
measured, PR corrected and WSR measured reflectivities, respectively. The correlation coefficient, $\rho$, and the number of WKH $\square$ SL[HOV $\square \square$ GHQRWHG $\square$ E $\backslash \square^{3} \mathrm{Q}^{2}$ RLQW' $\square \square$ DUH $\square$ DOVR $\square$ JLYH

Fig. 7 Same as Fig. 6 but for the case of rain at the height of $1.5 \mathrm{~km}$. The solid lines (black and white) are the computational results based on the Marshall-Palmer raindrop size distribution (1948).

Fig. 8 Mean of the PR-derived radar reflectivity factors vs. mean of WSR radar reflectivity factors at a height of $3 \mathrm{~km}$ from 210 TRMM overpasses for the period 1998-2007. Each data point represents an overpass event, where the size of the data point is proportional to the number of pixels in the overlap region in which both PR and WSR exceed their minimum detectable signals. Asterisk represents the weighted means. The theoretical results (solid line) are also plotted as the particle size distribution is assumed to be the Marshall-Palmer (1948) size distribution and raindrop to be oblate spheroid.

Fig. 9 Scatterplots of near surface rain rate (top panels) and their probability density functions (bottom panels) derived from 210 TRMM overpasses over Melbourne, Florida for the period 1998-2007. The results are divided into different storm types that are determined by the PR standard algorithm (2A23).

Fig.10 Mean of the PR-derived rain rate vs. mean of the WSR-derived rain from 210 TRMM overpasses for the period 1998-2007. Each data point represents an overpass event, where the size of the data point is proportional to the number of pixels in the overlap region in which both 
PR and WSR exceed the pre-defined rain rate of $0.5 \mathrm{~mm} / \mathrm{h}$ (PR threshold). Asterisk represents the weighted means.

Fig.11 Intersection area (lightly-shaded) of the PR swath on 24 January of 1998 with the WSR scan, which is used for the computation of the PR and WSR area-averaged rain.

Fig.12 Estimates of the area-averaged rain rate from the PR and WSR data from 210 overpasses during the period 1998-2007. The $\rho$ is the correlation coefficient, and asterisk represents the means of the data. 


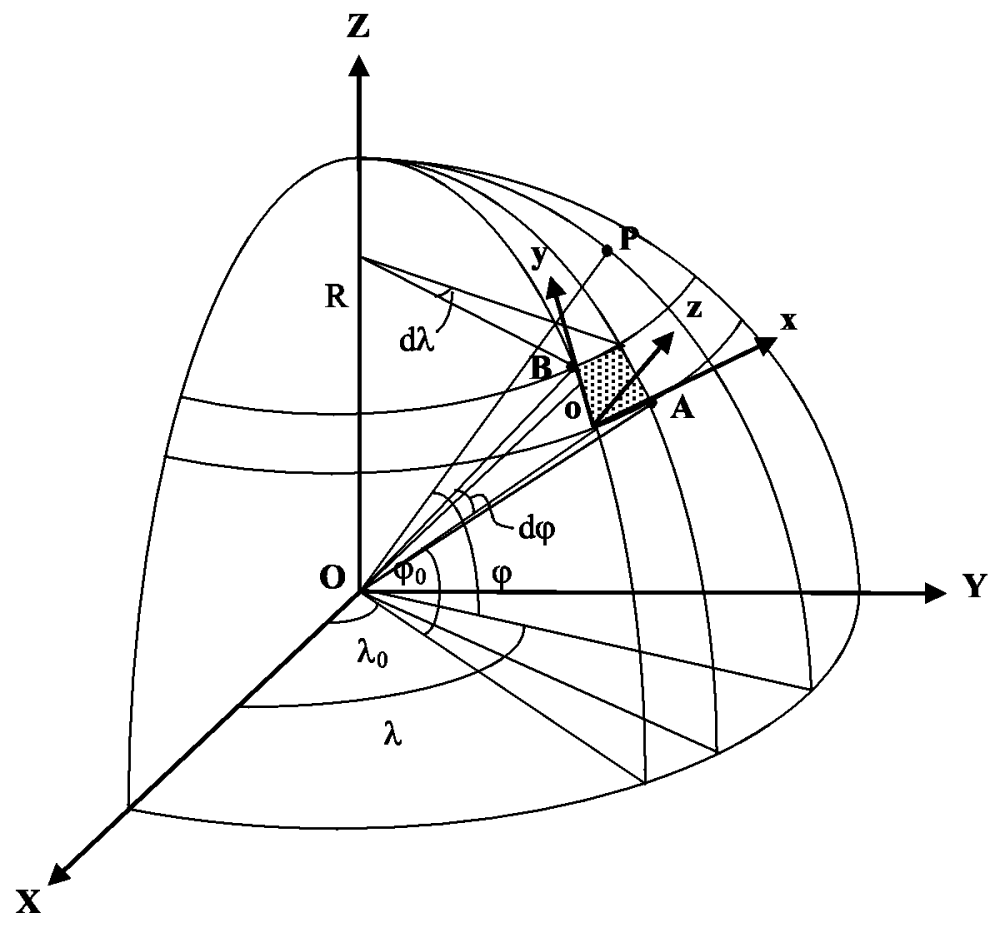

Fig.1 Schematic diagram of the earth coordinate system in which the latitude, $\varphi$, and longitude, $\lambda$, are defined. 


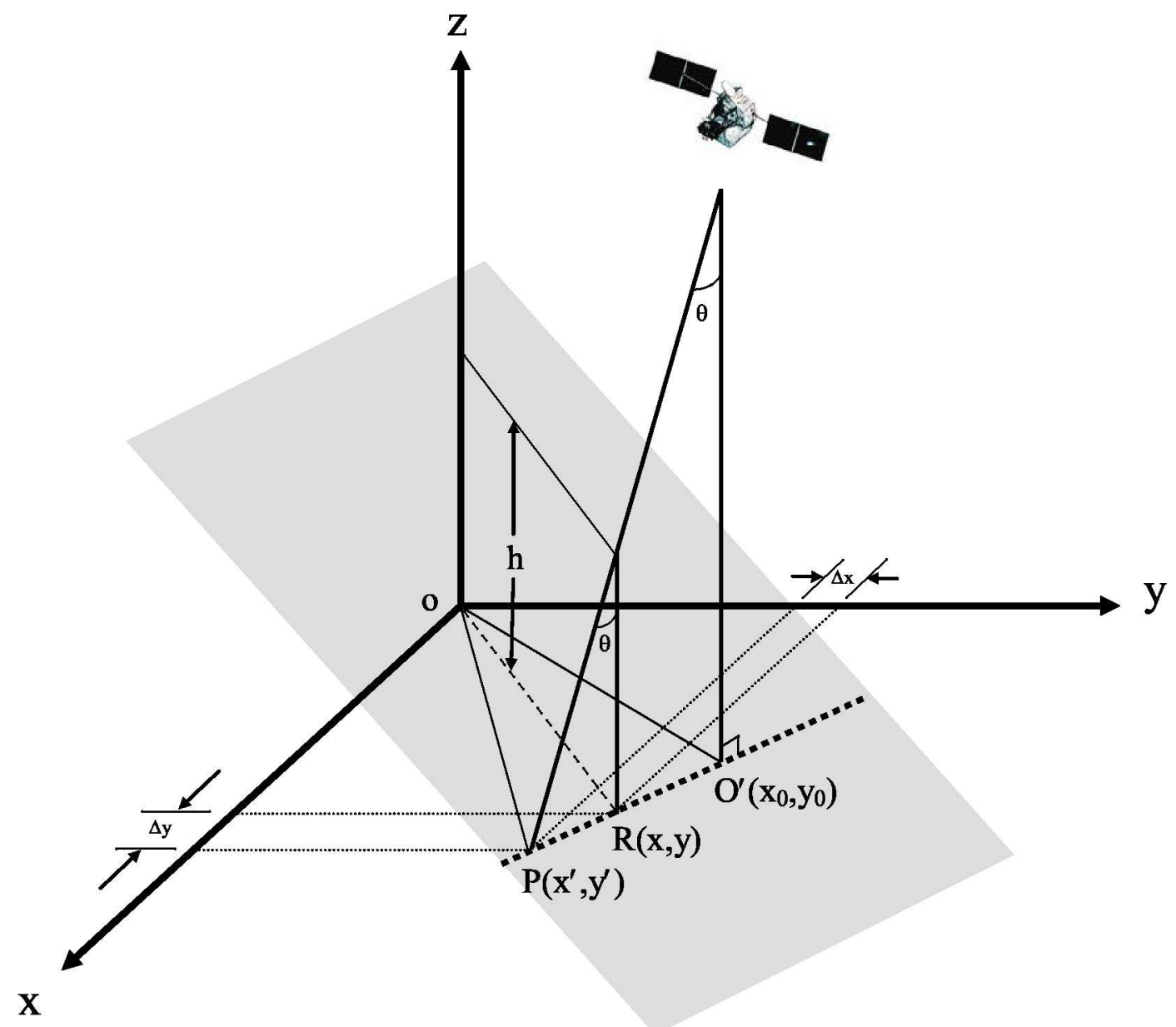

Fig. 2. Geometry for correction of PR offsets $(\Delta x$ and $\Delta y)$ in $x$ and $y$ axes at a height of $h$. 

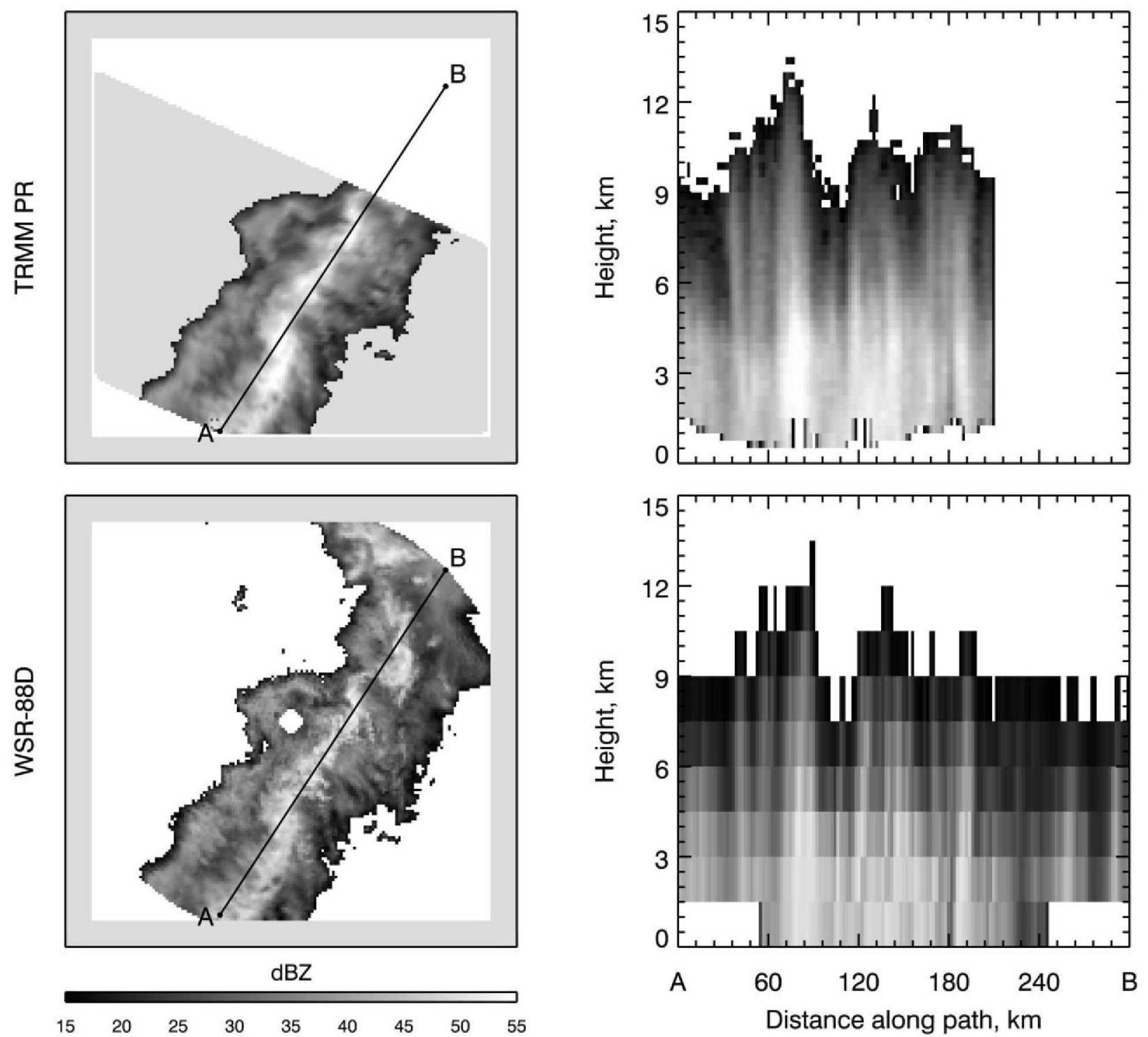

Fig. 3. Measurements of the PR (top) reflectivities, with attenuation correction, and the WSR88D (bottom) reflectivities (dBZ) for the March 9, 1998 overpass. Left: CAPPI display at a height of $3 \mathrm{~km}$; right: $\mathrm{RHI}$ display along the path $\mathrm{AB}$. 


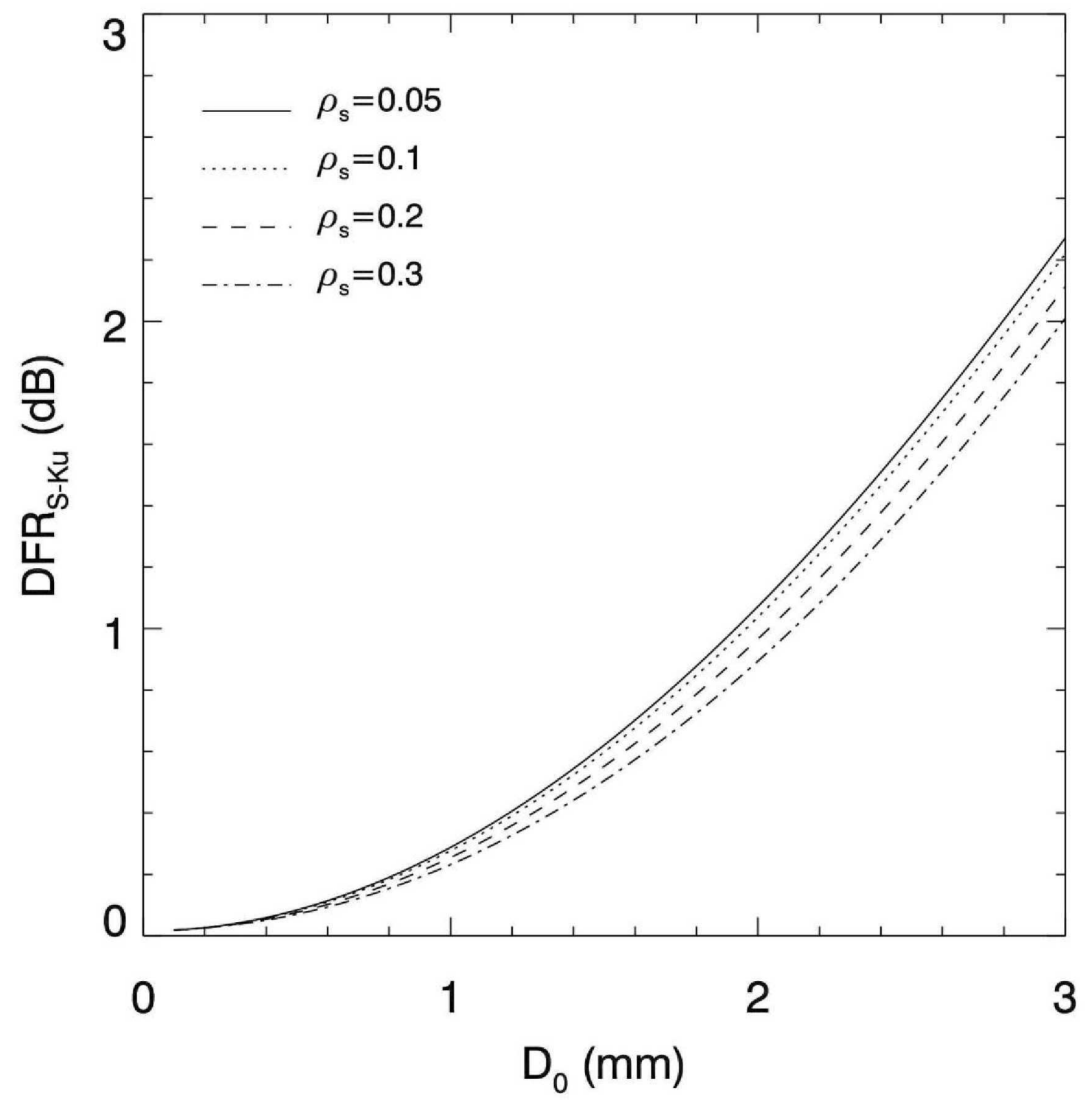

Fig. 4. DFR of $\mathrm{S}(3 \mathrm{GHz})$ and $\mathrm{Ku}(13.8 \mathrm{GHz})$ bands versus the median volume diameter $\left(\mathrm{D}_{0}\right)$ of snow particles as the snow mass density $\left(\rho_{\mathrm{s}}\right)$ varies from 0.05 to $0.3 \mathrm{~g} / \mathrm{cm}^{3}$ for the case of $\mu=0$. 


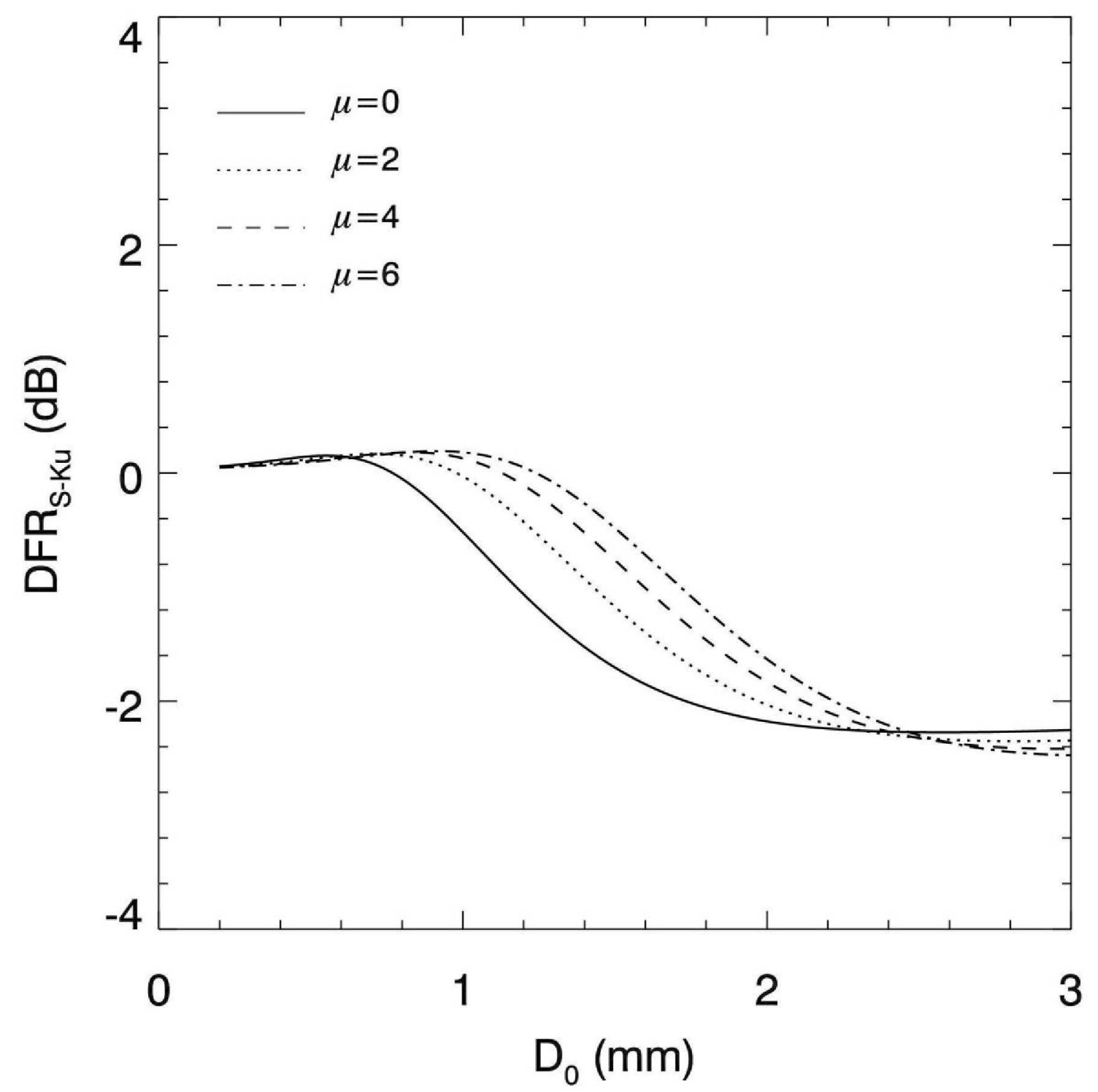

Fig.5 DFR of $\mathrm{S}(3 \mathrm{GHz})$ and $\mathrm{Ku}(13.8 \mathrm{GHz})$ bands versus the median volume diameter $\left(\mathrm{D}_{0}\right)$ of raindrops as the shape factor of the gamma size distribution is changed from 0 to 6 . 

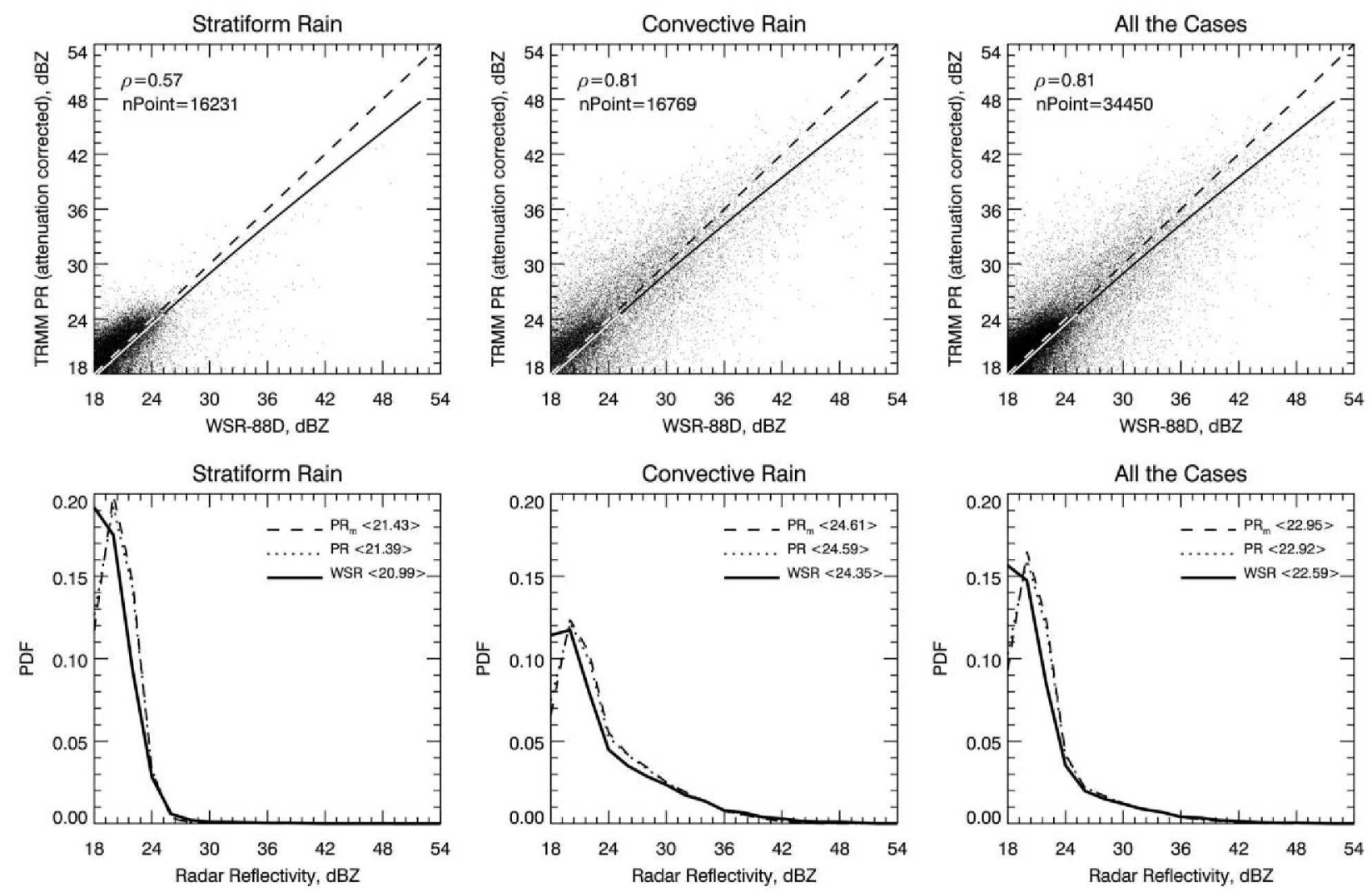

Fig. 6 Scatterplots of radar reflectivity factors (top panels) and their probability density functions (bottom panels) at a height of $7.5 \mathrm{~km}$ derived from 210 TRMM overpasses over Melbourne, Florida for the period 1998-2007. The solid lines (black and white) are the computational results based on the snow size distribution obtained by Gunn Marshall (1958) for a snow density of $0.3 \mathrm{~g} / \mathrm{cm}^{3}$. The results are divided into different storm types that are determined by the PR standard algorithm (2A23). ${ }^{3} \mathrm{PR}_{\mathrm{m}}{ }^{\prime}\left[{ }^{3} \mathrm{PR}^{\prime}\right.$ and ${ }^{3} \mathrm{WSR}^{\prime}$ refer to the PR measured, PR corrected and WSR measured reflectivities, respectively. The correlation coefficient, $\rho \square \square \mathrm{DQG} \square \mathrm{WKH} \square \mathrm{QXPEHU} \square \mathrm{RI} \square \mathrm{WKH} \square \mathrm{SL}\left[\mathrm{HOV} \square \square \mathrm{GHQRWHG} \square \mathrm{E} \backslash \square^{3} \mathrm{Q} 3 \mathrm{RLQW}{ }^{\prime} \square \square \mathrm{DUH} \square\right.$ 

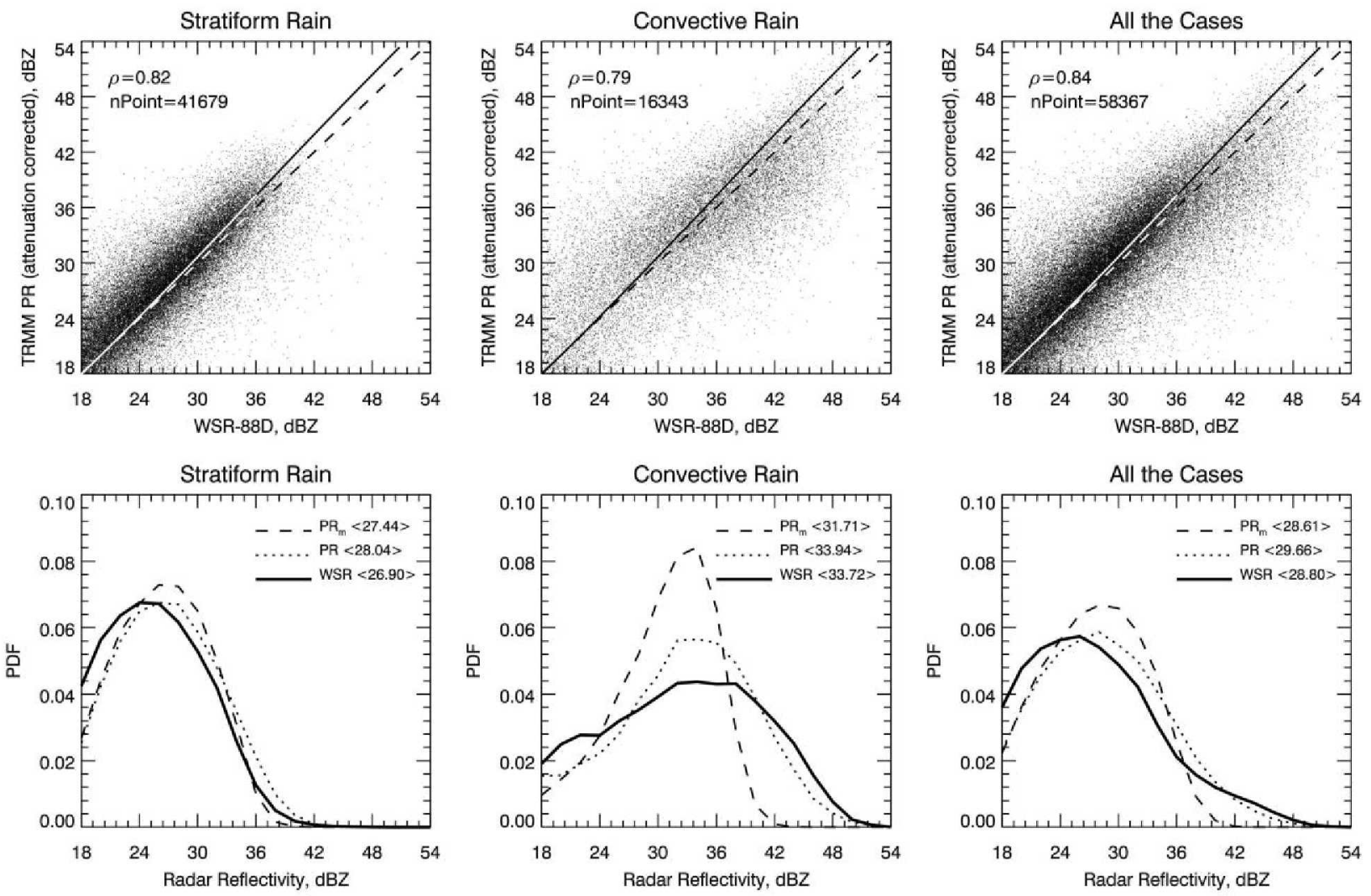

Fig. 7 Same as Fig. 6 but for the case of rain at the height of $1.5 \mathrm{~km}$. The solid lines (black and white) are the computational results based on the Marshall-Palmer raindrop size distribution (1948). 


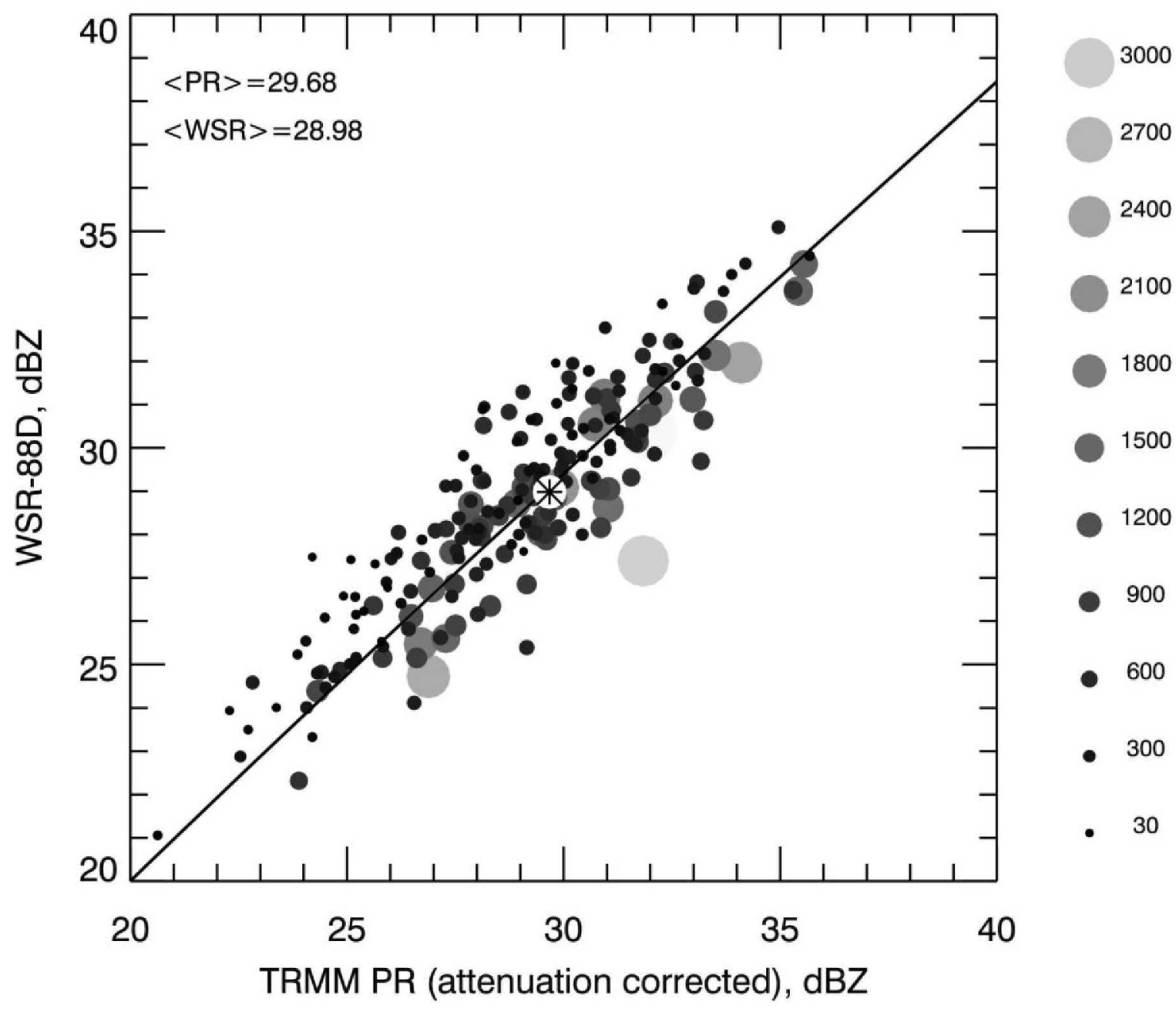

Fig.8 Mean of the PR-derived radar reflectivity factors vs. mean of WSR radar reflectivity factors at a height of $3 \mathrm{~km}$ from 210 TRMM overpasses for the period 1998-2007. Each data point represents an overpass event, where the size of the data point is proportional to the number of pixels as shown on the right in the overlap region in which both PR and WSR exceed their minimum detectable signals. Asterisk represents the weighted means. The theoretical results (solid line) are also plotted as the particle size distribution is assumed to be the Marshall-Palmer (1948) size distribution and raindrop to be oblate spheroid. 

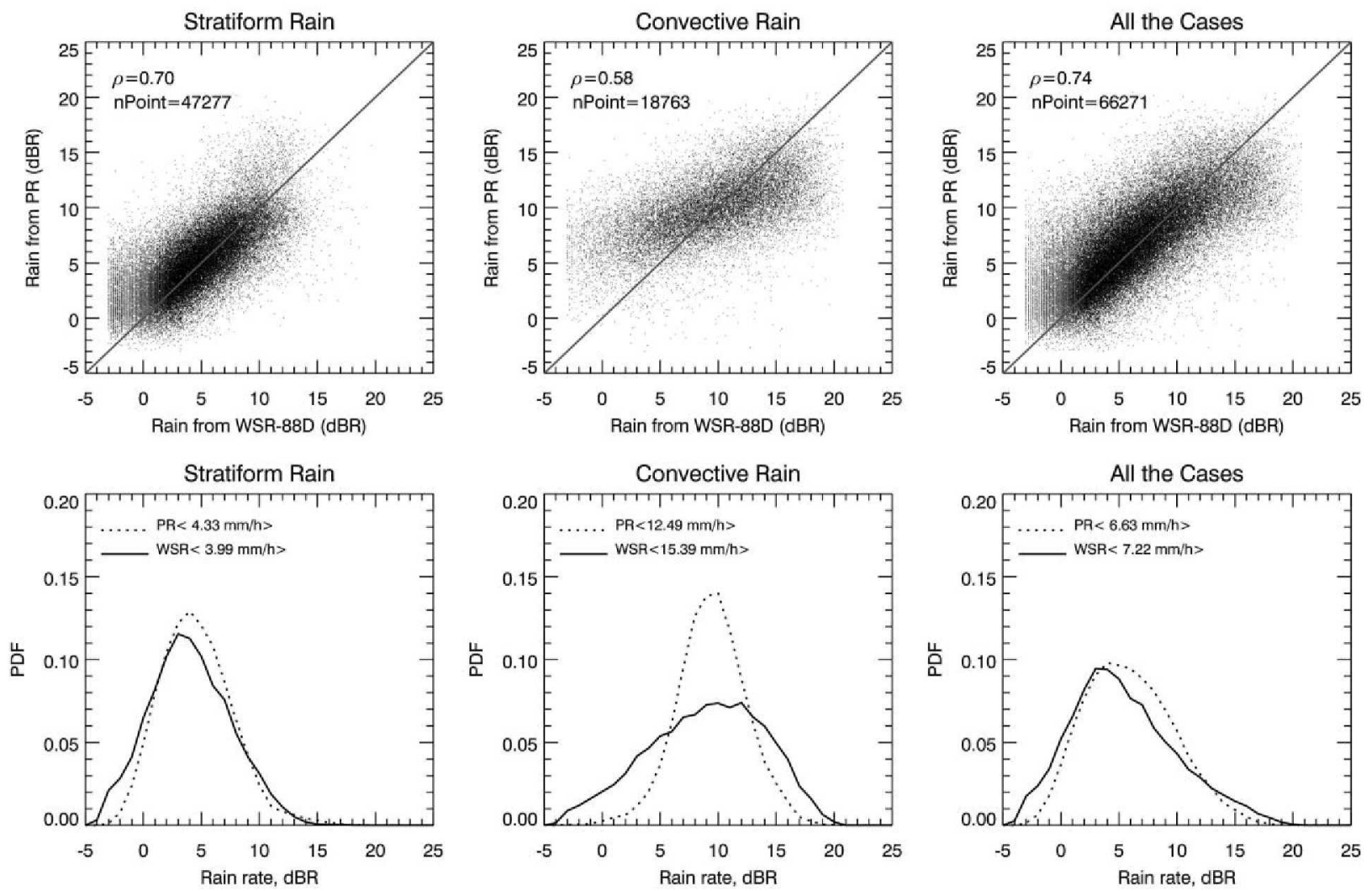

Fig. 9 Scatterplots of near surface rain rate (top panels) and their probability density functions (bottom panels) derived from 210 TRMM overpasses over Melbourne, Florida for the period 1998-2007. The results are divided into different storm types that are determined by the PR standard algorithm (2A23). 


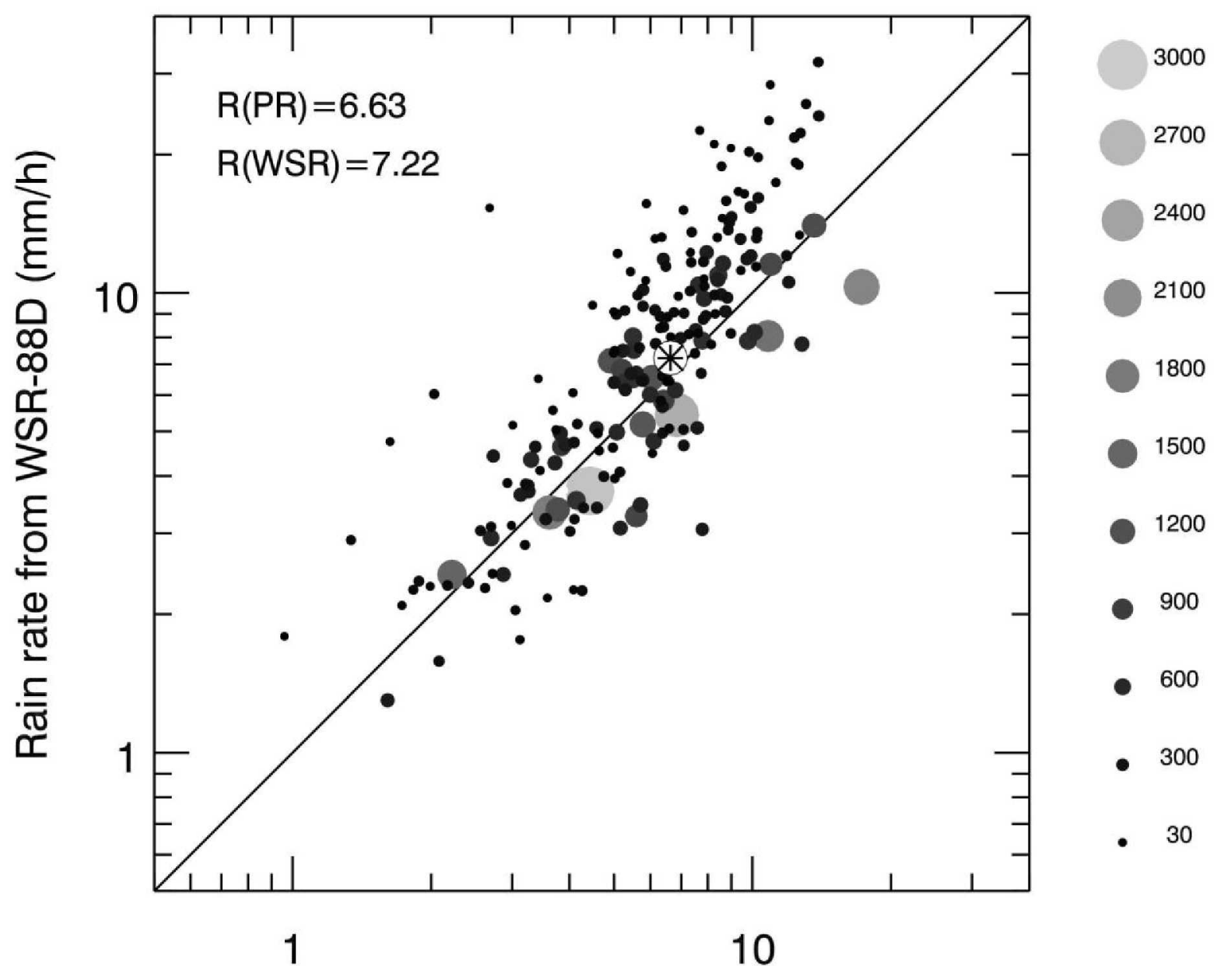

Rain rate from TRMM PR $(\mathrm{mm} / \mathrm{h})$

Fig.10 Mean of the PR-derived rain rate vs. mean of the WSR-derived rain from 210 TRMM overpasses for the period 1998-2007. Each data point represents an overpass event, where the size of the data point is proportional to the number of pixels as shown on the right in the overlap region in which both $P R$ and WSR exceed the pre-defined rain rate of $0.5 \mathrm{~mm} / \mathrm{h}$ (PR threshold). Asterisk represents the weighted means. 

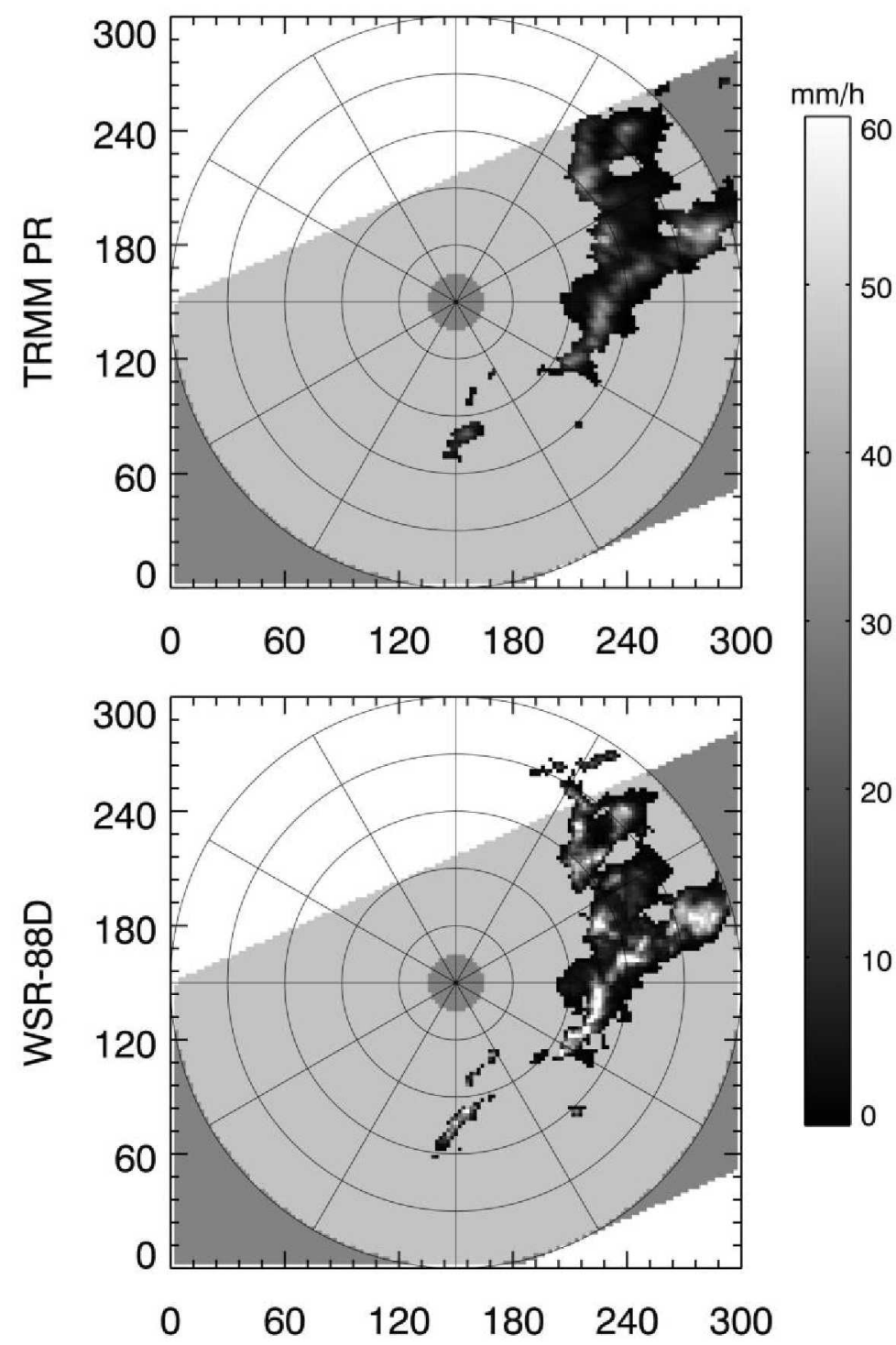

Fig.11 Intersection area (light-shaded) of the PR swath on 24 January of 1998 with the WSR scan, which is used for the computation of the PR and WSR area-averaged rain. 


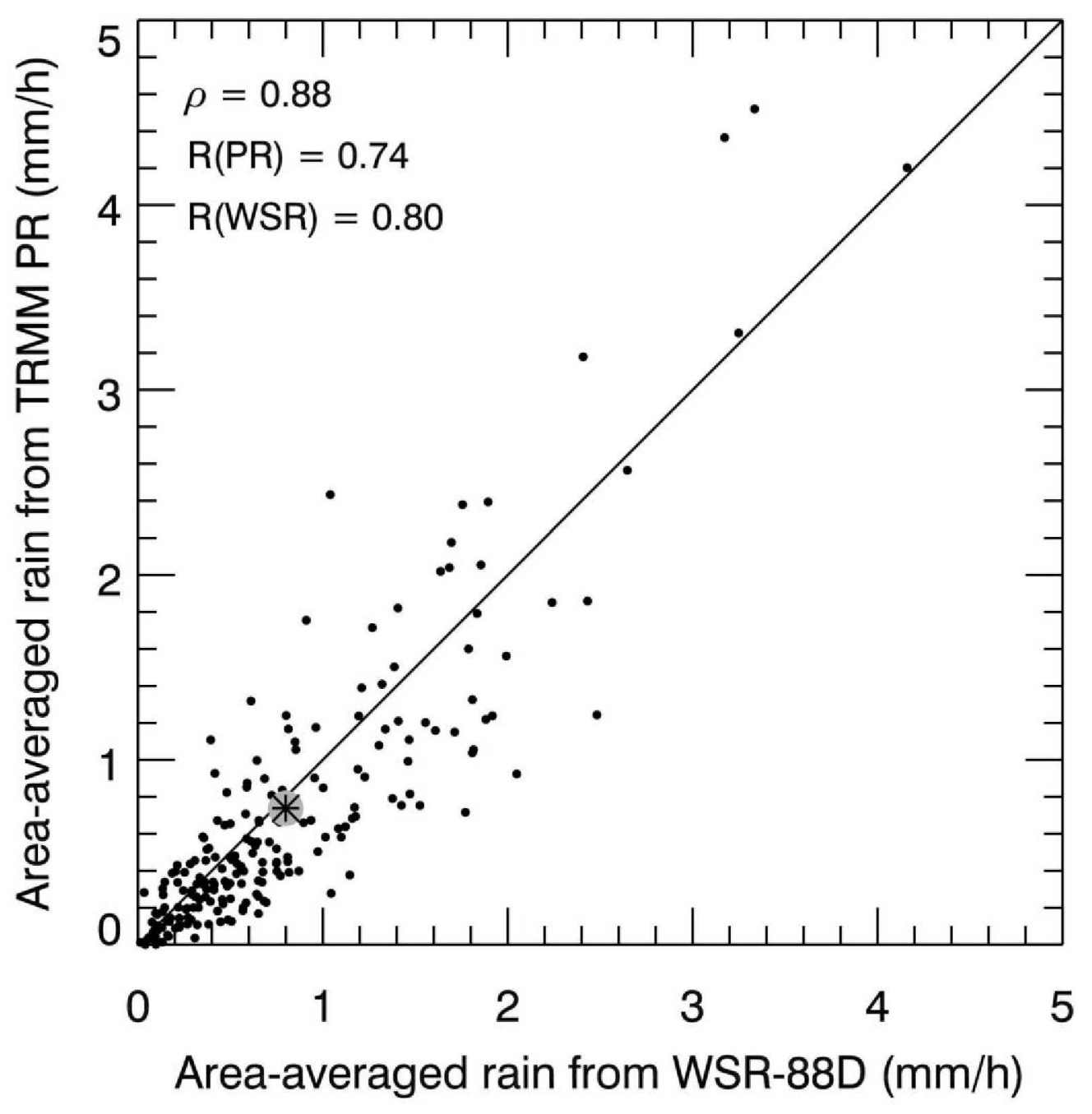

Fig.12 Estimates of the area-averaged rain rate from the PR and WSR data from 210 overpasses during the period 1998-2007. The $\rho$ is the correlation coefficient, and asterisk represents the means of the data. 
Liao, L., and R. Meneghini, 2009: Validation of TRMM Precipitation radar through comparison of its multiyear measurements with ground-based radar. J. Appl. Meteor. Climat., 48, 804-817.

\begin{abstract}
A procedure to accurately resample spaceborne and ground-based radar data is described, and then applied to the measurements taken from the Tropical Rainfall Measuring Mission (TRMM) Precipitation Radar (PR) and the ground-based Weather Surveillance Radar-1988 Doppler (WSR-88D or WSR) for the validation of the PR measurements and estimates. Through comparisons with the well-calibrated, non-attenuated WSR at Melbourne, Florida for the period 1998-2007, the calibration of the Precipitation Radar (PR) aboard the TRMM satellite is checked using measurements near the storm top. Analysis of the results indicates that the PR, after taking into account differences in radar reflectivity factors between the PR and WSR, has a small positive bias of $0.8 \mathrm{~dB}$ relative to the WSR, implying a soundness of the PR calibration in view of the uncertainties involved in the comparisons. Comparisons between the PR and WSR reflectivities are also made near the surface for evaluation of the attenuation-correction procedures used in the PR algorithms. It is found that the PR attenuation is accurately corrected in stratiform rain but is underestimated in convective rain, particularly in heavy rain. Tests of the PR estimates of rainfall rate are conducted through comparisons in the overlap area between the TRMM overpass and WSR scan. Analyses of the data are made both on a conditional basis, in which the instantaneous rain rates are compared only at those pixels where both the PR and WSR detect rain, and an unconditional basis, in which the area-averaged rain rates are estimated independently for the PR and WSR. Results of the conditional rain comparisons show that the PR-derived rain is about 9\% greater and $19 \%$ less than the WSR estimates for stratiform and convective storms, respectively. Overall, the PR tends to underestimate the conditional mean rain rate by $8 \%$ for all rain categories, a finding that conforms to the results of the area-averaged rain (unconditional) comparisons.
\end{abstract}

